\title{
Differential Proteomic Analysis of Hepatocellular Carcinomas from Ppp2r5d Knockout Mice and Normal (Knockout) Livers
}

\author{
CAROLINE LAMBRECHT ${ }^{1}$, GABRIELA BOMFIM FERREIRA ${ }^{2}$, JUDIT DOMÈNECH OMELLA ${ }^{1}$, \\ LOUIS LIBBRECHT ${ }^{3}$, RITA DE VOS ${ }^{4}$, RITA DERUA ${ }^{1}$, CHANTAL MATHIEU $^{2}$, \\ LUT OVERBERGH ${ }^{2}$, ETIENNE WAELKENS ${ }^{1}$ and VEERLE JANSSENS ${ }^{1,5}$ \\ ${ }^{1}$ Laboratory of Protein Phosphorylation and Proteomics, Department Cellular and Molecular Medicine, \\ University of Leuven (KU Leuven), Leuven, Belgium; \\ ${ }^{2}$ Clinical and Experimental Endocrinology, Department Clinical and Experimental Medicine, \\ University of Leuven (KU Leuven), Leuven, Belgium; \\ ${ }^{3}$ Department of Pathology, Université Catholique de Louvain (UCL), Brussels, Belgium; \\ ${ }^{4}$ Translational Cell and Tissue Research, Department Imaging and Pathology, \\ University of Leuven (KU Leuven), Leuven, Belgium; \\ ${ }^{5}$ LKI, KU Leuven Cancer Institute, Leuven, Belgium
}

\begin{abstract}
Background: Hepatocellular carcinoma (HCC) is the major type of primary liver cancer. Mice lacking the tumor-suppressive protein phosphatase $2 A$ subunit B56ठ (Ppp2r5d) spontaneously develop HCC, correlating with increased c-MYC oncogenicity. Materials and Methods: We used two-dimensional difference gel electrophoresis-coupled matrix-assisted laser desorption/ionization time-of-flight mass spectrometry to identify differential proteomes of livers from wild-type, non-cancerous and HCC-affected B56ठ knockout mice. Results: A total of 23 proteins were differentially expressed/regulated in liver between wild-type and non-cancerous knockout mice, and 119 between noncancerous and HCC knockout mice ('cancer proteins'). Overlap with our reported differential transcriptome data was poor. Overall, $56 \%$ of cancer proteins were reported before in HCC proteomics studies; $44 \%$ were novel. Gene Ontology analysis revealed cancer proteins mainly associated with liver metabolism (18\%) and mitochondria (15\%). Ingenuity Pathway Analysis identified 'cancer' and
\end{abstract}

This article is freely accessible online.

Correspondence to: Professor V. Janssens, Gasthuisberg O\&N1, Herestraat 49, PO-box 901, B-3000 Leuven, Belgium. Tel: +32 16330684, e-mail: Veerle.janssens@kuleuven.be or Professor E. Waelkens, Gasthuisberg O\&N1, Herestraat 49, PO-box 901, B-3000 Leuven, Belgium. Tel: +32 16330645, e-mail: Etienne.waelkens@ kuleuven.be

Key Words: HCC, PP2A, tumor suppressor, Ppp2r5d, B56ठ subunit, 2D-DIGE, biomarker, mouse model, hepatocarcinogenesis, fibrinogen, liver, proteomics. 'gastrointestinal disease' as top hits. Conclusion: We identified several proteins for further exploration as novel potential HCC biomarkers, and independently underscored the relevance of Ppp2r5d knockout mice as a valuable hepatocarcinogenesis model.

Hepatocellular carcinoma (HCC) is the most common primary liver cancer, and the second leading cause of cancer-related death worldwide (1). Most patients with HCC are diagnosed at an advanced stage due to asymptomatic features during neoplastic progression, and hence their prognosis is grim. Curative therapies, including orthotopic liver transplantation, surgical resection and local destruction, can only be offered to early diagnosed patients, and is complicated by high recurrence rates. Advanced or non-resectable HCC is associated with a poor prognosis due to broad resistance to chemotherapeutic agents (25). Several risk factors for HCC development have been established, including viral hepatitis $\mathrm{B}$ and $\mathrm{C}$ infection, aflatoxin B1 exposure, excessive alcohol abuse and nonalcoholic fatty liver disease, all giving rise, to some extent, to (chronic) liver inflammation, cirrhosis or liver injury. Only in about $15 \%$ of cases does HCC arise in a context of normal liver (6).

In general, the molecular mechanisms resulting in HCC initiation and progression remain incompletely understood (7). In recent years, comparative genomic profiling, gene expression and exome mutational analysis studies in human HCC samples have enabled HCCs to be classified into two different molecular subgroups, termed 'proliferation' and 'nonproliferation' [reviewed in $(8,9)$ ]. Tumors from the first class are highly heterogeneous and are associated with poor prognosis. They show increased protein kinase B $(\mathrm{AKT}) / \mathrm{mammalian}$ target of rapamycin (mTOR), hepatocyte 
growth factor receptor (MET), transforming growth factor $\beta$ (TGF $\beta$ ), insulin-like growth factor (IGF), rat sarcoma virus oncogene (RAS)/mitogen-activated protein kinase (MAPK) or NOTCH signaling, high-level amplifications of chromosomes 11q13 [fibroblast growth factor 19 gene (FGF19)/cyclin D1 gene (CCND1)] or 6p21 [vascular endothelial growth factor A gene (VEGFA)], and frequent aberrations in chromosomes 1 or 8 [myelocytomatosis oncogene $(M Y C)]$. Tumors from the second class are less aggressive, better differentiated and are associated with a better outcome. They feature activated WNT signaling (mostly via $\beta 1$-catenin gene (CTNNB1) mutations) or chromosome 7 gain [epidermal growth factor receptor gene $(E G F R)]$. The most prevalent mutations in HCC pathogenesis include those in the telomerase reverse transcriptase gene (TERT) promoter, tumor protein p53 gene (TP53), CTNNB1, axin1 gene (AXIN1), and AT-rich interaction domain $1 \mathrm{~A}$ and 2 genes (ARIDIA and ARID2) $(10,11)$. Up to 10 different mutational signatures associated with HCC have been identified in various studies [reviewed in (8)]. Additional proteomics studies have further contributed to HCC classification and biomarker discovery (12-33). Disappointingly, however, these insights have not yet resulted in improved, molecular-targeted therapies.

To help unraveling the molecular mechanisms underlying hepatocarcinogenesis in different pre-clinical settings in vivo, rodent HCC models remain valuable tools. This is especially true for models in which the human pathology is well mimicked, and considering that available human HCC tissues can be limiting. In addition to chemically or virally induced liver cancer models, several genetically engineered transgenic, knockout (KO) or knockin (KI) mouse models of HCC have been described, each featuring its own specific tumor initiation/progression, tumor microenvironment and mechanistic characteristics [reviewed in $(34,35)$ ]. These models have significantly contributed to identifying molecular signatures relevant to HCC via cross-species comparative and integrative analyses with human data. Moreover, they have facilitated the discovery of potential biomarkers for diagnostic or prognostic purposes.

Recently, we described significantly increased spontaneous HCC development, arising within a largely normal liver context (36), in Ppp2r5d KO mice. These mice lack expression of the regulatory B56 subunit of protein phosphatase 2A (PP2A) (37), a large family of predominantly tumor-suppressive Ser/Thr protein phosphatases $(38,39)$ regulating cell signaling processes in many organs and tissues (40). Tumor-suppressive PP2A holoenzymes negatively control a large variety of oncogenic pathways, relevant for HCC, including phosphatidylinositol 3-kinase (PI3K)/AKT, mTOR/p70 ribosomal S6 Kinase (p70 S6K), MAPextracellular signal-regulated kinase (MEK)/extracellular signal-regulated kinase (ERK) and WNT signaling (41).
Mechanistically, we identified lack of PP2A-B568-driven glycogen synthase kinase-3 $\beta$ (GSK-3 $\beta$ ) dephosphorylation on Ser9 (resulting in constitutive GSK-3 $\beta$ inactivation) as the likely tumor-predisposing factor, which affected the GSK-3 $\beta$ substrate c-MYC in all HCC-bearing livers. Indeed, in the presence of a serendipitous oncogenic alteration affecting cMYC Ser62 phosphorylation, lack of c-MYC Thr-58 phosphorylation by GSK-3 $\beta$ resulted in c-MYC stabilization and Ser62 hyperphosphorylation in all tumors (36). c-MYC is a well-established oncogenic driver in liver $(42,43)$, whose activation is essential for malignant conversion of dysplastic nodules into early HCC (44). Conversely, PP2A-B56 appears to act as a tumor suppressor in liver, keeping oncogenic activation of c-MYC in check (36).

HCCs from several c-MYC transgenic mouse models show interesting molecular overlaps with human HCCs of both the better and the poorer survival groups (45). In the present study, we subjected B56 $\mathrm{KO}$ HCC samples, paired non-cancerous B56 $\delta \mathrm{KO}$ liver tissue, and wild-type (WT) livers to an unbiased quantitative proteomics approach using two-dimensional difference gel electrophoresis (2D-DIGE). With this approach, we aimed to provide further insights into the mechanisms of hepatocarcinogenesis in Ppp2r5d KO mice, as well as into the suitability of this model to mimic human HCC.

\section{Materials and Methods}

Sampling of biological material. All protocols involving mice were in compliance with the KU Leuven University Animal Care and Usage Committee (ECD projects P034-2008 and P168-2013). The genetic background of the WT and Ppp2r5d KO mice was mixed (C57BL/6;129 - 87.5\%;12.5\%) (F3) (36). All sampled mice were male and between 18 and 24 months old. Mice were anaesthetized with an intraperitoneal injection of pentobarbital (Nembutal) and transcardially perfused with ice-cold saline ( $\mathrm{NaCl} 0.9 \%$ Baxter). Livers were entirely removed, or in the case of a macroscopically visible liver lesion, both the lesion and a part of the normal surrounding liver were kept separately. For each tissue, one part was fixed in $4 \%$ paraformaldehyde at $4{ }^{\circ} \mathrm{C}$ overnight, washed the next day and stored in $70 \%$ ethanol until paraffin embedding; another part was snap-frozen in liquid nitrogen and kept at $-80^{\circ} \mathrm{C}$ until further use.

Histopathology. Hematoxylin/eosin-stained sections (4 $\mu \mathrm{m})$ of paraffin-embedded liver were examined by a liver pathologist for the presence of pathological lesions. For the Ppp2r5d KO samples, the 'healthy', non-tumor state, as well as the HCC state, were additionally confirmed on a cryosection of the snap-frozen material that was eventually lysed for 2D-DIGE use.

Electron microscopy. Small samples from the snap-frozen tissues were thawed and fixed in $2.5 \%$ glutaraldehyde (in $0.1 \mathrm{M}$ phosphate buffer, $\mathrm{pH} 7.2$ ) at $4^{\circ} \mathrm{C}$ overnight. After $1 \mathrm{~h}$ post-fixation in $2 \%$ osmium tetroxide (in $0.1 \mathrm{M}$ phosphate buffer, $\mathrm{pH} 7.2$ ) at $4^{\circ} \mathrm{C}$, the samples were dehydrated in a graded series of ethanol, and embedded in epoxy resin. Ultrathin sections of 50-60 nm were cut, 
stained with uranyl acetate and lead citrate, and examined at $50 \mathrm{kV}$ using a Zeiss EM 900 electron microscope (Carl Zeiss AG, Oberkochen, Germany).

Protein extraction and 2D-DIGE. Frozen liver tissues were weighed, homogenized and sonicated on ice in lysis buffer [7 $\mathrm{M}$ urea, $2 \mathrm{M}$ thiourea, $40 \mathrm{mM}$ Tris, 1\% dithiothreitol (DTT), 4\% CHAPS] containing protease and phosphatase inhibitor cocktail (Roche). Samples were centrifuged for $15 \mathrm{~min}$ at $20,000 \times g$ at $4^{\circ} \mathrm{C}$. The supernatant was collected and desalted by dialysis (PlusOne Mini Dialysis kit; GE Healthcare, Chicago, IL, USA), and the protein concentration was determined with the Bradford method. Fifty micrograms of protein was labeled with 200 pmol of amine reactive cyanine dyes Cy3 (samples of condition 1) or Cy5 (samples of condition 2), whereas $50 \mu \mathrm{g}$ of an internal standard was labeled with 200 pmol of Cy2 (GE Healthcare). The internal standard consisted of a pool of equal amounts of all 12 samples. A total of 12 gels were run, each with three samples (condition 1 sample, condition 2 sample and internal standard). Thus, a WT liver sample $(n=4)$ was compared with a healthy KO liver sample $(\mathrm{n}=4)(4$ gels), as well as with a KO HCC sample $(n=4)$ (4 gels); and a healthy KO liver sample $(n=4)$ was pairwise compared with a KO HCC sample $(n=4)$ (4 gels). IPG strips were rehydrated overnight in $450 \mu \mathrm{l}$ rehydratation buffer [7 M urea, 2 M thiourea, $4 \%$ CHAPS, $0.5 \%$ immobilized $\mathrm{pH}$ gradient (IPG) buffer with either 1\% DTT for IPG strips pH 4-7 or 1.2\% DeStreak (GE Healthcare) for IPG strips $\mathrm{pH}$ 6-9]. The pooled labelled samples containing sample loading buffer were loaded into individual $24 \mathrm{~cm}$ IPG strips using anodic cup loading. Isoelectric focusing (first dimension) was carried out on an Ettan IPGphor II manifold (GE Healthcare). After isoelectric focusing, the IPG strips were equilibrated during two intervals of $15 \mathrm{~min}$ each in equilibration buffer (7 M urea, $2 \mathrm{M}$ thiourea, $4 \%$ CHAPS, $0.5 \%$ IPG buffer, $0.02 \%$ bromophenol blue), and either 1\% DTT (pH strip 4-7) or 1.2\% DeStreak (pH strip 6-9). Equilibrated strips were placed on top of a $12.5 \%$ sodium dodecyl sulfate polyacrylamide gel and separated on an Ettan DaltSix System (GE Healthcare). Gels were scanned on a Typhoon 9400 gel imager at $100 \mu \mathrm{m}$ pixel size (GE Healthcare). Prior to analysis with DeCyder V 7.0 software (GE Healthcare), gel images were cropped using ImageQuant TL (GE Healthcare). Spot detection and matching was performed automatically using the "Batch Processor" module of DeCyder V 7.0 software followed by careful manual rematching of unmatched spots and wrongly matched spots. Proteins in spots were accepted as being differentially expressed when showing a statistically significant $(p<0.05)$ increase or decrease when compared to the control in at least $75 \%$ of the spot maps (Supplementary Table: available at https://gbiomed.kuleuven.be/lambrecht-cgp).

Spot digestion and protein identification by matrix-assisted laser desorption/ionization (MALDI) time-of-flight (TOF)/TOF analysis. A pick list was generated and exported into Spot Picker V1.20 software operating the Ettan Spot Picker (GE Healthcare). Spots were picked in MilliQ water, transferred to $100 \mu$ l of fixation solution (50\% methanol, 5\% acetic acid and 45\% MilliQ) and rinsed three times with MilliQ water and three times with acetonitrile (ACN) (Sigma-Aldrich, St. Louis, MO, USA). The gel pieces were hydrated in a $100 \mathrm{mM} \mathrm{NH} \mathrm{HCO}_{3}$ solution for 10 min followed by a dehydratation step in $100 \%$ ACN for 10 min with vigorous vortexing. This step was repeated twice prior to dehydrating the gel pieces in a SpeedVac (Thermo Fisher Scientific, Bremen, Germany). The gel pieces were rehydrated in digestion buffer $[50 \mathrm{mM}$
$\mathrm{NH}_{4} \mathrm{HCO}_{3}, 5 \mathrm{mM} \mathrm{CaCl}, 5 \mathrm{ng} / \mu \mathrm{l}$ of sequencing grade modified trypsin (Promega, Madison, WI, USA)] on ice for $45 \mathrm{~min}$, followed by overnight incubation at $37^{\circ} \mathrm{C}$. The resulting peptides were extracted out of the gel plugs in four steps: once with $50 \mathrm{mM}$ $\mathrm{NH}_{4} \mathrm{HCO}_{3}$, twice with $50 \% \mathrm{ACN} / 5 \%$ formic acid, and once with 95\% ACN $/ 5 \%$ formic acid (30 min each). Supernatants were dried in a SpeedVac. Upon concentrating and desalting the tryptic fragments using ZipTip C-18 (Millipore, Milford, MA, USA), the samples were mixed in a 1:1 ratio with a-cyano-4-hydroxycinnamic acid matrix (saturated solution in $50 \% \mathrm{ACN} / 2.5 \%$ trifluoroacetic acid in HPLC water), spotted onto the MALDI target plate, and allowed to air dry. MS/MS analyses were performed on a 4800 MALDI TOF/TOF (Applied Biosystems, Waltham, MA, USA). Measurements were taken in the positive ion mode between 900 and $3000 \mathrm{~m} / \mathrm{z}$. Sequences were automatically acquired by scanning first in MS mode and selecting the 15 most intense ions for MS/MS using an exclusion list of peaks arising from tryptic autodigestion. Air was used as the collision gas, whereas the collision energy was adapted automatically. Data interpretation was carried out using the GPS Explorer software and database searching was carried out using MASCOT. MS/MS searches were conducted with the following settings: Swiss-Prot-TrEMBL as databases, taxonomy Mus musculus, MS/MS tolerance for precursor ions was set on 0.2 $\mathrm{Da}$ and for fragment ions 0.4 Da, methionine oxidation as variable modification, and carbamidomethylation of cysteine as fixed modification. Only peptides with MASCOT scores above the identity threshold and probability-based MOWSE scores greater than the given cut-off value for MS/MS fragmentation data were retained and taken as significant $(p<0.05)$. Using these parameters, 118 picked spots could be linked to at least one reliable protein identification (Supplementary Table: available at https:// gbiomed.kuleuven.be/lambrecht-cgp). For proteins confirmed to be present within different spots, either in horizontal spot 'trains' or dispersed over the whole gel map (32 in total), an average relative abundance value was calculated, keeping up-regulated values separate from down-regulated ones (when applicable). These average values were used for eventual representation in Table I.

Immunoblotting. Protein lysates were resolved on 4-12\% 2,2bis(hydroxymethyl)-2,2',2"'-nitrilotriethanol, 2-bis(2-hydroxyethyl) amino-2-(hydroxymethyl)-1,3-propanediol, bis(2-hydroxyethyl)aminotris(hydroxymethyl)methane (BIS-TRIS) gels (BioRad, Hercules, CA, USA) and transferred to polyvinylidene difluoride membranes (GE Healthcare) by wet blotting. The membranes were blocked in 5\% milk in tris(hydroxymethyl)aminomethane-buffered saline (TBS)/Tween buffer $\left(0.1 \%\right.$ Tween-20 in TBS) at $4^{\circ} \mathrm{C}$ overnight. After washing in TBS/Tween, incubation with the primary antibody was performed in TBS/Tween containing 5\% bovine serum albumin. The following primary antibodies were used: polyclonal rabbit anti-B568 (46) (dilution: 1/2,000); monoclonal mouse anti-PP2A A and PP2A C (clones C5.3D10 and F2.6A10, dilution: 1/3,000; kind gifts of Dr. Stephen Dilworth, UK); monoclonal mouse anti-vinculin (dilution: 1/10,000; Sigma-Aldrich), polyclonal rabbit anti-fructose-1,6-bisphosphatase 1 (FBP1) (dilution: 1/1,000; Abcam, Cambridge, UK); mouse monoclonal antiphosphoglycerate mutase 2 (PGM2) (sc-376718; dilution: 1/500; Santa Cruz Biotechnologies, La Jolla, CA, USA); mouse monoclonal anti- $S$ adenosylmethionine synthase 1 (METK1) (sc-166452, dilution 1/500; Santa Cruz Biotechnologies); polyclonal rabbit anti-phospho-MEK1/2 S217/S221 (dilution 1/1,000; Cell Signaling Technology, Danvers, MA, USA); polyclonal rabbit anti-phospho-ERK1/2 T202/Y204 (dilution 
Table I. Representation of 129 differentially expressed proteins [green: up-regulated, $p<0.05$; red: down-regulated, $p<0.05$; grey: not dysregulated, $p>0.05$; bold: marker proteins confirmed in other proteomics studies of mouse, rat or human hepatocellular carcinoma, including references (last column)].

\begin{tabular}{|c|c|c|c|c|c|c|c|c|}
\hline \multirow[b]{2}{*}{$\begin{array}{l}\text { Gene } \\
\text { name }\end{array}$} & \multirow[b]{2}{*}{$\begin{array}{c}\text { UniProtKB } \\
\text { name }\end{array}$} & \multirow[b]{2}{*}{$\begin{array}{c}\text { Accession } \\
\text { number }\end{array}$} & \multirow[b]{2}{*}{$\begin{array}{l}\text { Full protein } \\
\text { name }\end{array}$} & \multicolumn{2}{|c|}{ Average ratio } & \multirow[b]{2}{*}{$\begin{array}{c}\text { Number } \\
\text { of } \\
\text { spots }\end{array}$} & \multirow[b]{2}{*}{$\begin{array}{l}\text { Functional } \\
\text { classes GO } \\
\text { annotation }\end{array}$} & \multirow[b]{2}{*}{ Reference } \\
\hline & & & & $\mathrm{HCC} / \mathrm{KO}$ & KO/WT & & & \\
\hline Ppp2r1A & 2AAA & Q76MZ3 & PP2A $65 \mathrm{kDa}$ regulatory subunit $\mathrm{A} \alpha$ or $\mathrm{A} \beta$ & 2.24 & -1.15 & 2 & Cell cycle & Conflict (25) \\
\hline Ccdc15 & CCDC15 & Q8C9M2 & Coiled-coiled domain protein 15 & 4.92 & -1.55 & 1 & Cell cycle & NEW \\
\hline Ahctfl & ELYS & Q8CJF7 & Protein ELYS & 2.88 & -1.32 & 1 & Cell cycle & NEW \\
\hline Rbbp7 & RBBP7 & Q60973 & Histone-binding protein RBBP7 & 2.51 & -1.02 & 1 & Cell cycle & NEW \\
\hline Serpinalb & A1AT2 & P22599 & Alpha-1-antitrypsin 1-2 & 2.68 & -1.64 & 1 & Coagulation & $\begin{array}{c}(13,14,22 \\
25-27,32)\end{array}$ \\
\hline Serpinc1 & ANT3 & P32261 & Antithrombin-III & 2.06 & -1.14 & 3 & Coagulation & NEW \\
\hline Anxa3 & ANXA3 & O35639 & Annexin A3 & 1.9 & 1.28 & 1 & Coagulation & (15) \\
\hline Fgg & FIBG & Q8VCM7 & Fibrinogen gamma chain & 7.28 & -1.1 & 1 & Coagulation & (13) \\
\hline$T c p 1$ & TCPA & P11983 & T-Complex protein 1 subunit alpha & -2.56 & -1.83 & 1 & Coagulation & (15) \\
\hline Cct8 & TCPQ & P42932 & T-Complex protein 1 subunit theta & 2.13 & -1.28 & 2 & Coagulation & NEW \\
\hline Anxall & ANXA11 & P97384 & Annexin A11 & 1.9 & 1.28 & 1 & Cytoskeleton & NEW \\
\hline Anxa4 & ANXA4 & P97429 & Annexin A4 & 3.91 & -1.48 & 1 & Cytoskeleton & Conflict (20) \\
\hline$C d h 23$ & CAD23 & Q99PF4 & Cadherin-23 & 1.83 & -1.07 & 1 & Cytoskeleton & NEW \\
\hline Col6a2 & $\mathrm{CO} 6 \mathrm{~A} 2$ & Q02788 & Collagen alpha-2 (VI) chain & -3.7 & 1.71 & 1 & Cytoskeleton & NEW \\
\hline Des & DESM & $\mathrm{P} 31001$ & Desmin & 3.51 & -1.19 & 1 & Cytoskeleton & NEW \\
\hline Ezr & EZRI & P26040 & Ezrin & -1.5 & -1.01 & 1 & Cytoskeleton & NEW \\
\hline Krt18 & $\mathrm{K} 1 \mathrm{C} 18$ & P05784 & Keratin, type I cytoskeletal 18 & 3.69 & -1.28 & 1 & Cytoskeleton & $(19,26,31)$ \\
\hline Krt2 & K22E & Q3TTY5 & Keratin, type II cytoskeletal 2 epidermal & 3.51 & -1.19 & 1 & Cytoskeleton & (27) \\
\hline Krt77 & $\mathrm{K} 2 \mathrm{C} 1 \mathrm{~B}$ & Q6IFZ6 & Keratin, type II cytoskeletal 1b & 3.51 & -1.19 & 1 & Cytoskeleton & $(27)$ \\
\hline$K r t 8$ & $\mathrm{~K} 2 \mathrm{C} 8$ & P11679 & Keratin type II, cytoskeletal 8 & 4.03 & -1.19 & 5 & Cytoskeleton & $(15,17,19,24)$ \\
\hline$R d x$ & RADI & P26043 & Radixin & -1.93 & -1.03 & 1 & Cytoskeleton & (19) \\
\hline Tubala & TBA1A & P68369 & Tubulin alpha-1A chain & 2.58 & -1.02 & 3 & Cytoskeleton & NEW \\
\hline Tubala & TBA1A & P68369 & Tubulin alpha-1A chain & -2.66 & 1.33 & 1 & Cytoskeleton & \\
\hline Tubb2a & TBB2A & Q7TMM9 & Tubulin beta $2 \mathrm{~A}$ chain & 2.76 & -1.03 & 2 & Cytoskeleton & $(25,33)$ \\
\hline Tubb2c & TBB2C & AAH05547 & Tubulin beta $2 \mathrm{C}$ chain & 2.76 & -1.03 & 2 & Cytoskeleton & $(25,26)$ \\
\hline Tubb5 & TBB5 & P99024 & Tubulin beta-5 chain & 1.94 & -1.06 & 1 & Cytoskeleton & (25) \\
\hline $\operatorname{Vim}$ & VIME & P20152 & Vimentin & 2.47 & -1.03 & 2 & Cytoskeleton & $(17,26,27)$ \\
\hline$W d r 1$ & WDR1 & O88342 & WD Repeat-containing protein 1 & 1.17 & -1.35 & 2 & Cytoskeleton & \\
\hline Calr & CALR & P14211 & Calreticulin & 2.41 & -1.25 & 1 & ER/protein folding & (31) \\
\hline Dnajc3 & DNAJC3 & Q91YW3 & DnaJ homolog subfamily $\mathrm{C}$ member 3 & 5.39 & -1.25 & 1 & $\mathrm{ER} /$ protein folding & (21) \\
\hline Hsp90b1 & ENPL & P08113 & Endoplasmin & 3.4 & -1.24 & 1 & $\mathrm{ER} /$ protein folding & $(21,27)$ \\
\hline Erp44 & ERP44 & Q9D1Q6 & Endoplasmic reticulum resident protein 44 & -1.17 & -1.41 & 1 & $\mathrm{ER} /$ protein folding & \\
\hline Hspa5 & GRP78 & P20029 & 78-kDa Glucose-regulated protein & 3.46 & -1.41 & 2 & ER/protein folding & $\begin{array}{l}(14,22,24 \\
26,27,31)\end{array}$ \\
\hline Hspa8 & HSP7C & P63017 & Heat-shock cognate 71-kDa protein & 4.08 & -1.08 & 1 & $\mathrm{ER} /$ protein folding & $\begin{array}{c}(21,23,26 \\
27,31)\end{array}$ \\
\hline$P 4 h b$ & PDIA1 & P09103 & Protein disulfide-isomerase & 3.25 & -1.63 & 5 & $\mathrm{ER} /$ protein folding & $\begin{array}{c}(19,20,26 \\
27,31)\end{array}$ \\
\hline Pdia3 & PDIA3 & P27773 & Protein disulfide-isomerase $\mathbf{A 3}$ & 2.80 & -1.32 & 4 & ER/protein folding & $(17,31)$ \\
\hline Txndc5 & TXND5 & Q91W90 & Thioredoxin domain-containing protein 5 & -1.17 & -1.41 & 1 & ER/protein folding & \\
\hline Enol & ENOA & P17182 & Alpha-enolase & -2.11 & 1.23 & 2 & Glucose metabolism & $(17,26)$ \\
\hline Eno3 & ENOB & P21550 & Beta-enolase & -1.76 & 1.19 & 1 & Glucose metabolism & NEW \\
\hline Fbpl & FBP1 & Q9QXD6 & Fructose-1,6-bisphosphatase 1 & -1.4 & -1.46 & 2 & Glucose metabolism & $\begin{array}{c}(12,13,15 \\
17-20,22,26 \\
27,31-33)\end{array}$ \\
\hline$P g k 1$ & PGK1 & P09411 & Phosphoglycerate kinase 1 & -3.4 & 1.27 & 1 & Glucose metabolism & $(26,31)$ \\
\hline Pgm2 & PGM2 & Q7TSV4 & Phosphoglucomutase-2 & -2.95 & -1.08 & 1 & Glucose metabolism & NEW \\
\hline Tpil & TPIS & P17751 & Triosephosphate isomerase & -2.05 & -1.12 & 1 & Glucose metabolism & $(\mathbf{2 1})$ \\
\hline Apoal & APOA1 & Q00623 & Apolipoprotein A-1 & 15.57 & -0.83 & 5 & Lipids & $(22,25,31)$ \\
\hline Cpne1 & CPNE1 & Q8C166 & Copine-1 & 1.86 & -1.29 & 1 & Lipids & NEW \\
\hline Aspg & LPP60 & A0JNU3 & 60-kDa Lysophospholipase & 2.5 & -1.42 & 1 & Lipids & (21) \\
\hline
\end{tabular}


Table I. Continued

\begin{tabular}{|c|c|c|c|c|c|c|c|c|}
\hline \multirow[b]{2}{*}{$\begin{array}{l}\text { Gene } \\
\text { name }\end{array}$} & \multirow[b]{2}{*}{$\begin{array}{l}\text { UniProtKB } \\
\text { name }\end{array}$} & \multirow[b]{2}{*}{$\begin{array}{c}\text { Accession } \\
\text { number }\end{array}$} & \multirow[b]{2}{*}{$\begin{array}{l}\text { Full protein } \\
\text { name }\end{array}$} & \multicolumn{2}{|c|}{ Average ratio } & \multirow[b]{2}{*}{$\begin{array}{c}\text { Number } \\
\text { of } \\
\text { spots }\end{array}$} & \multirow[b]{2}{*}{$\begin{array}{l}\text { Functional } \\
\text { classes GO } \\
\text { annotation }\end{array}$} & \multirow[b]{2}{*}{ Reference } \\
\hline & & & & $\mathrm{HCC} / \mathrm{KO}$ & KO/WT & & & \\
\hline Got1 & AATC & P05201 & Aspartate aminotransferase, cytoplasmic & 1.7 & -1.14 & 1 & Liver metabolism & Conflict (20) \\
\hline$A d k$ & ADK & P55264 & Adenosine kinase & -2.38 & -1.24 & 2 & Liver metabolism & (25) \\
\hline Apmap & APMAP & Q9D7N9 & $\begin{array}{l}\text { Adipocyte plasma-membrane } \\
\text { associated protein }\end{array}$ & -3.44 & 1.77 & 1 & Liver metabolism & NEW \\
\hline Assl & ASSY & P16460 & Argininosuccinate synthase & -3.4 & 1.27 & 1 & Liver metabolism & $\begin{array}{c}(17,20,26 \\
28,31)\end{array}$ \\
\hline Bhmt & BHMT1 & O35490 & $\begin{array}{l}\text { Betaine homocysteine } \\
S \text {-methyltransferase } 1\end{array}$ & -3.4 & 1.27 & 1 & Liver metabolism & $\begin{array}{c}13,14,18,20 \\
21,26,29 \\
30,33)\end{array}$ \\
\hline Cndp2 & CNDP2 & Q9D1A2 & Cytosolic non-specific dipeptidase & 2.35 & 1.18 & 1 & Liver metabolism & NEW \\
\hline Dpys & DPYS & Q9EQF5 & Dihydropyrimidinase & -1.73 & -1.1 & 1 & Liver metabolism & NEW \\
\hline Ces7 & EST7 & EDL11102 & Carboxylesterase 7 & 2.94 & -1.32 & 2 & Liver metabolism & NEW \\
\hline Aldh1ll1 & FTHFD & Q8R0Y6 & 10-formyltetrahydrofolate dehydrogenase & -2.98 & 1.13 & 2 & Liver metabolism & $(15,25,27)$ \\
\hline Gnmt & GNMT & Q9QXF8 & Glycine $N$-methyl transferase & -3.62 & 1.09 & 1 & Liver metabolism & $\begin{array}{l}(13-15,22 \\
25,26,31)\end{array}$ \\
\hline Gda & GUAD & Q9R111 & Guanine deaminase & -3.09 & 1.9 & 1 & Liver metabolism & NEW \\
\hline Ephx2 & HYES & P34914 & Epoxide hydrolase 2 & 2.3 & -1.27 & 1 & Liver metabolism & (31) \\
\hline$M d h 1$ & MDHC & P14152 & Malate dehydrogenase, cytoplasmic & -1.92 & 1.07 & 1 & Liver metabolism & $(15,18,22,25)$ \\
\hline Mat1a & METK1 & Q91X83 & $\begin{array}{l}S \text {-Adenosylmethionine synthase } \\
\text { isoform type-1 }\end{array}$ & 7.28 & -1.1 & 1 & Liver metabolism & $(12,31)$ \\
\hline Mat1a & METK1 & Q91X83 & $\begin{array}{l}S \text {-Adenosylmethionine synthase } \\
\text { isoform type-1 }\end{array}$ & -3.09 & 1.9 & 1 & Liver metabolism & $(13,14)$ \\
\hline P4ha2 & P4HA2 & Q60716 & Prolyl 4-hydroxylase subunit alpha 2 & 2.88 & -1.32 & 1 & Liver metabolism & (18) \\
\hline Pbldl & PBLD1 & Q9DCG6 & $\begin{array}{l}\text { Phenazine biosynthesis-like } \\
\text { containing protein } 1\end{array}$ & -2 & 1 & 1 & Liver metabolism & (26) \\
\hline$P a h$ & $\mathrm{PH} 4 \mathrm{H}$ & P16331 & Phenylalanine-4-hydroxylase & 3.59 & 1.15 & 1 & Liver metabolism & $(15,19)$ \\
\hline Pon3 & PON3 & Q62087 & Serum paraoxonase/lactonase 3 & 4 & 1.05 & 1 & Liver metabolism & NEW \\
\hline Ctps1 & PYRG1 & P70698 & CTP synthase 1 & 2.04 & -1.06 & 1 & Liver metabolism & NEW \\
\hline Ahcy & SAHH & P50247 & Adenosyl homocysteinase & -2.41 & 1.33 & 1 & Liver metabolism & $(13,22,31)$ \\
\hline Uap1l1 & UAP1L & Q3TW96 & $\begin{array}{l}\text { UDP- } N \text {-acetylhexosamine pyropho- } \\
\text { sphorylase-like protein } 1\end{array}$ & 4.6 & 1.2 & 1 & Liver metabolism & (15) \\
\hline Acsml & ACSM1 & Q91VA0 & $\begin{array}{l}\text { Acyl-coenzyme A synthetase } \\
\text { ACSM1, mitochondrial }\end{array}$ & -1.15 & -1.35 & 1 & Mitochondria & \\
\hline Metapld & AMP1D & Q9CPW9 & $\begin{array}{l}\text { Methionine aminopeptidase 1D, } \\
\text { mitochondrial }\end{array}$ & 1.43 & -1.07 & 1 & Mitochondria & NEW \\
\hline Atp5pd & ATP5H & Q9DCX2 & ATP synthase subunit $d$, mitochondrial & -1.1 & -1.19 & 1 & Mitochondria & NEW \\
\hline Hspdl & $\mathrm{CH} 60$ & P63038 & 60-kDa Heat-shock protein, mitochondrial & 14.6 & 1.2 & 1 & Mitochondria & (23) \\
\hline Cps1 & CPS1 & Q8C196 & $\begin{array}{l}\text { Carbamoyl-phosphate synthase, } \\
\text { mitochondrial }\end{array}$ & -2.36 & 1.71 & 12 & Mitochondria & $\begin{array}{c}(14,17,19 \\
22,25,26 \\
29,31)\end{array}$ \\
\hline Sdha & SDHA & Q8K2B3 & $\begin{array}{l}\text { Succinate dehydrogenase flavoprotein } \\
\text { subunit, mitochondrial }\end{array}$ & -1.39 & -1.36 & 3 & Mitochondria & NEW \\
\hline Hspa9 & GRP75 & P38647 & Stress-70 protein, mitochondrial & 8.54 & -1.35 & 2 & Mitochondria & $(22,26)$ \\
\hline Hmgcs 2 & HMGCS2 & P54869 & $\begin{array}{l}\text { Hydroxymethylglutaryl-CoA } \\
\text { synthase, mitochondrial }\end{array}$ & 1.7 & -1.14 & 1 & Mitochondria & $(19,23,29)$ \\
\hline Immt & IMMT & Q8CAQ8 & Mitochondrial inner membrane protein & -1.5 & -1.01 & 1 & Mitochondria & NEW \\
\hline Mcccl & MCCA & Q99MR8 & $\begin{array}{l}\text { Methylcrotonoyl-CoA carboxylase } \\
\text { subunit } \alpha, \text { mitochondrial }\end{array}$ & 5.92 & 1.52 & 1 & Mitochondria & $(21)$ \\
\hline$N d u f s 2$ & NDUS2 & Q91WD5 & $\begin{array}{l}\text { NADH dehydrogenase iron-sulfur } \\
\text { protein } 2 \text {, mitochondrial }\end{array}$ & -3.44 & 1.77 & 1 & Mitochondria & NEW \\
\hline Ndufv2 & NDUFV2 & Q9D6J6 & $\begin{array}{l}\text { NADH dehydrogenase } \\
\text { flavoprotein } 2 \text {, mitochondrial }\end{array}$ & 35.28 & -1.3 & 1 & Mitochondria & NEW \\
\hline Oat & OAT & P29758 & $\begin{array}{l}\text { Ornithine aminotransferase, } \\
\text { mitochondrial }\end{array}$ & 1.52 & -1.19 & 1 & Mitochondria & $(15,19,25)$ \\
\hline
\end{tabular}


Table I. Continued

\begin{tabular}{|c|c|c|c|c|c|c|c|c|}
\hline \multirow[b]{2}{*}{$\begin{array}{l}\text { Gene } \\
\text { name }\end{array}$} & \multirow[b]{2}{*}{$\begin{array}{l}\text { UniProtKB } \\
\text { name }\end{array}$} & \multirow[b]{2}{*}{$\begin{array}{l}\text { Accession } \\
\text { number }\end{array}$} & \multirow[b]{2}{*}{$\begin{array}{l}\text { Full protein } \\
\text { name }\end{array}$} & \multicolumn{2}{|c|}{ Average ratio } & \multirow[b]{2}{*}{$\begin{array}{c}\text { Number } \\
\text { of } \\
\text { spots }\end{array}$} & \multirow[b]{2}{*}{$\begin{array}{l}\text { Functional } \\
\text { classes GO } \\
\text { annotation }\end{array}$} & \multirow[b]{2}{*}{ Reference } \\
\hline & & & & $\mathrm{HCC} / \mathrm{KO}$ & KO/WT & & & \\
\hline$O g d h$ & ODO1 & Q60597 & $\begin{array}{l}\text { 2-oxoglutarate dehydrogenase, } \\
\text { mitochondrial }\end{array}$ & -1.81 & 1.66 & 1 & Mitochondria & \\
\hline Dlst & $\mathrm{ODO} 2$ & Q9D2G2 & $\begin{array}{l}\text { Dihydrolipoyllysine-residue succinyl- } \\
\text { transferase component of 2-oxoglutarate } \\
\text { dehydrogenase complex, mitochondrial }\end{array}$ & 1.59 & -1.17 & 1 & Mitochondria & \\
\hline Otc & OTC & P11725 & $\begin{array}{l}\text { Ornithine carbamoyl } \\
\text { transferase, mitochondrial }\end{array}$ & -2.54 & 1.01 & 1 & Mitochondria & $(22,25,31)$ \\
\hline$P c$ & PYC & Q05920 & Pyruvate carboxylase, mitochondrial & -2.33 & 1.18 & 2 & Mitochondria & NEW \\
\hline Sardh & SARDH & Q99LB7 & $\begin{array}{l}\text { Sarcosine dehydrogenase, } \\
\text { mitochondrial }\end{array}$ & -2.98 & 1.08 & 4 & Mitochondria & $\begin{array}{c}(19,22, \\
25-27,31)\end{array}$ \\
\hline Stoml2 & STML2 & Q99JB2 & Stomatin-like protein 2 & -3.40 & 1.27 & 1 & Mitochondria & NEW \\
\hline Sucla2 & SUCB1 & Q9Z2I9 & $\begin{array}{l}\text { Succinyl-CoA ligase [ADP-forming] } \\
\text { subunit beta, mitochondrial }\end{array}$ & 1.19 & -1.35 & 1 & Mitochondria & \\
\hline Acatl & THIL & Q8QZT1 & $\begin{array}{l}\text { Acetyl-CoA acetyltransferase, } \\
\text { mitochondrial }\end{array}$ & -3.11 & 1.06 & 1 & Mitochondria & $(13-15,17)$ \\
\hline Uqcrfsl & UQCRFS1 & Q9CR68 & $\begin{array}{l}\text { Cytochrome B-C1 complex subunit } \\
\text { Rieske, mitochondrial }\end{array}$ & -2 & 1 & 1 & Mitochondria & NEW \\
\hline Hnrnpk & HNRPK & P61979 & Heterogenous nuclear ribonucleoprotein $\mathrm{K}$ & 2.15 & -1.28 & $3 \mathrm{~m}$ & nRNA process./translat. & (15) \\
\hline Eif $4 b$ & IF4B & Q8BGD9 & Eukaryotic translation initiation factor 4B & 2.14 & -1.37 & $1 \mathrm{~m}$ & nRNA process./translat. & NEW \\
\hline RplpO & RLA0 & P14869 & 60S Acidic ribosomal protein $\mathrm{P0}$ & 1.43 & -1.07 & $1 \mathrm{~m}$ & nRNA process./translat. & (28) \\
\hline Ruvbl2 & RUVB2 & Q9WTM5 & RuvB-like 2 & 7.28 & -1.1 & $1 \mathrm{~m}$ & nRNA process./translat. & (16) \\
\hline Hars1 & SYHC & Q61035 & Histidyl-tRNA synthetase, cytoplasmic & 2.35 & 1.18 & $1 \mathrm{~m}$ & nRNA process./translat. & NEW \\
\hline Gars1 & SYG & P41250 & Glycyl-tRNA synthetase & 2.43 & 1.09 & $1 \mathrm{~m}$ & nRNA process./translat. & $(\mathbf{1 5})$ \\
\hline$W d r 12$ & WDR12 & Q9JJA4 & Ribosome biogenesis protein WDR12 & 2.85 & -1.16 & $1 \mathrm{~m}$ & nRNA process./translat. & NEW \\
\hline Abhd14b & ABHEB & Q8VCR7 & $\begin{array}{l}\alpha / \beta \text { Hydrolase domain-containing } \\
\text { protein 14B }\end{array}$ & -2.34 & -1.15 & 1 & Not classified & $(17,25,31)$ \\
\hline Crtap & CRTAP & Q9CYD3 & Cartilage-associated protein & -3.09 & 1.9 & 1 & Not classified & NEW \\
\hline Efhd2 & EFHD2 & Q9D8Y0 & EF-Hand domain-containing protein D2 & 2.35 & -1 & 1 & Not classified & NEW \\
\hline Ahsg & FETUA & P29699 & Alpha-2-HS-glycoprotein & 4.27 & -1.08 & 1 & Not classified & NEW \\
\hline$H 2-K 1$ & HA1B & P01901 & $\begin{array}{l}\mathrm{H}-2 \text { Class I histocompatibility } \\
\text { antigen, K-B } \alpha \text { chain }\end{array}$ & -3.09 & 1.9 & 1 & Not classified & NEW \\
\hline N/A & IGHA & P01878 & Ig Alpha chain $\mathrm{C}$ region & 2.02 & -1.01 & 1 & Not classified & NEW \\
\hline Iigp1 & IIGP1 & Q9QZ85 & Interferon-inducible GTPase 1 & 1.59 & -1.17 & 1 & Not classified & \\
\hline Gaa & LYAG & P70699 & Lysosomal alpha-glucosidase & 2.5 & -1.42 & 1 & Not classified & (17) \\
\hline Kat6a & MYST3 & Q8BZ21 & Histone acetyltransferase KAT6A or MYST3 & 3 & -1.14 & 1 & Not classified & NEW \\
\hline Pebpl & PEBP1 & P70296 & $\begin{array}{l}\text { Phosphatidylethanolamine- } \\
\text { binding protein } 1\end{array}$ & 1.51 & -1.15 & 1 & Not classified & $(\mathbf{2 5})$ \\
\hline Rgn & RGN & Q64374 & Regucalcin & -5.14 & 1.03 & 3 & Not classified & $\begin{array}{l}(13,15,22 \\
25,31,32)\end{array}$ \\
\hline $\operatorname{Rgn}$ & RGN & Q64374 & Regucalcin & 8.4 & -1.18 & 1 & Not classified & (19) \\
\hline Gdil & GDIA & P50396 & Rab GDP dissociation inhibitor alpha & 2.09 & -1.2 & 2 & Receptor linked & NEW \\
\hline Gdi2 & GDIB & Q61598 & Rab GDP dissociation inhibitor beta & 1.52 & -1.19 & 1 & Receptor linked & NEW \\
\hline Atp6vla & VATA & P50516 & V-Type proton ATPase catalytic subunit A & 5.52 & 1.22 & 1 & Receptor linked & NEW \\
\hline Atp6v1b2 & VATB2 & P62814 & $\begin{array}{l}\text { V-Type proton ATPase subunit B, } \\
\text { brain isoform }\end{array}$ & 2.35 & 1.18 & 1 & Receptor linked & NEW \\
\hline Cat & CATA & P24270 & Catalase & -2.19 & -1.07 & 2 & Redox regulation & $\begin{array}{l}(13-15,20 \\
22,32)\end{array}$ \\
\hline Dhdh & DHDH & Q9DBB8 & $\begin{array}{l}\text { Trans-1,2-dihydrobenzene-1,2- } \\
\text { diol dehydrogenase }\end{array}$ & -1.4 & -1.33 & 1 & Redox regulation & (15) \\
\hline Gpxl & GPX1 & P11352 & Glutathione peroxidase 1 & -1.98 & -1.10 & 3 & Redox regulation & $(15,25,31)$ \\
\hline Grhpr & GRHPR & Q91Z53 & $\begin{array}{l}\text { Glyoxylate reductase/hydroxy- } \\
\text { pyruvate reductase }\end{array}$ & 1.7 & -1.14 & 1 & Redox regulation & Conflict (26) \\
\hline $\operatorname{Prdx} 2$ & PRDX2 & Q61171 & Peroxiredoxin 2 & 1.51 & -1.15 & 1 & Redox regulation & $(24,25)$ \\
\hline
\end{tabular}




\begin{tabular}{|c|c|c|c|c|c|c|c|c|}
\hline \multirow[b]{2}{*}{$\begin{array}{l}\text { Gene } \\
\text { name }\end{array}$} & \multirow[b]{2}{*}{$\begin{array}{l}\text { UniProtKB } \\
\text { name }\end{array}$} & \multirow[b]{2}{*}{$\begin{array}{l}\text { Accession } \\
\text { number }\end{array}$} & \multirow[b]{2}{*}{$\begin{array}{l}\text { Full protein } \\
\text { name }\end{array}$} & \multicolumn{2}{|c|}{ Average ratio } & \multirow[b]{2}{*}{$\begin{array}{c}\text { Number } \\
\text { of } \\
\text { spots }\end{array}$} & \multirow[b]{2}{*}{$\begin{array}{l}\text { Functional } \\
\text { classes GO } \\
\text { annotation }\end{array}$} & \multirow[b]{2}{*}{ Reference } \\
\hline & & & & $\mathrm{HCC} / \mathrm{KO}$ & $\mathrm{KO} / \mathrm{WT}$ & & & \\
\hline$A l b$ & ALBU & P07724 & Serum albumin & 4.94 & -1.32 & 22 & Transport & $\begin{array}{l}(14,22,26 \\
27,31)\end{array}$ \\
\hline Ehd4 & EHD4 & Q9EQP2 & EH domain-containing protein 4 & -1.2 & -1.33 & 1 & Transport & \\
\hline$H p x$ & HEMO & Q91X72 & Hemopexin & 2.93 & -1.15 & 5 & Transport & (25) \\
\hline Selenbp1 & SELENBP1 & P17563 & $\begin{array}{l}\text { Methanethiol oxidase/selenium- } \\
\text { binding protein } 1\end{array}$ & 3.60 & -1.06 & 2 & Transport & (19) \\
\hline Snx6 & SNX6 & Q6P8X1 & Sorting nexin-6 & 1.59 & -1.17 & 1 & Transport & \\
\hline $\mathrm{Tg}$ & THYG & O08710 & Thyroglobulin & -5.74 & 1.17 & 1 & Transport & NEW \\
\hline$T f$ & TRFE & Q921I1 & Serotransferrin & $-1.5-$ & $-1,01$ & 1 & Transport & $(13,32)$ \\
\hline Tf & TRFE & Q921I1 & Serotransferrin & 5.92 & 1.52 & 1 & Transport & $(15,22,26,31)$ \\
\hline$G c$ & VTDB & P21614 & Vitamin D-binding protein & 4.27 & -1.08 & 1 & Transport & (22) \\
\hline Cops 4 & CSN4 & O88544 & COP9 Signalosome complex subunit 4 & 4 & 1.05 & 1 & $\begin{array}{l}\text { Ubiquitination/ } \\
\text { degradation }\end{array}$ & NEW \\
\hline Psmc4 & PRS6B & P54775 & 26S Proteasome regulatory subunit 6B & 3.69 & -1.28 & 1 & $\begin{array}{l}\text { Ubiquitination/ } \\
\text { degradation }\end{array}$ & NEW \\
\hline Psmc2 & PRS7 & P46471 & 26S Proteasome regulatory subunit 7 & 1.52 & -1.19 & 1 & $\begin{array}{l}\text { Ubiquitination/ } \\
\text { degradation }\end{array}$ & NEW \\
\hline Psmd13 & PSD13 & Q9WVJ2 & $\begin{array}{l}\text { 26S Proteasome non-ATPase } \\
\text { regulatory subunit } 13\end{array}$ & 1.50 & -1.06 & 1 & $\begin{array}{l}\text { Ubiquitination/ } \\
\text { degradation }\end{array}$ & NEW \\
\hline Psmb4 & PSMB4 & P99026 & Proteasome subunit beta type 4 & 1.97 & 1 & 1 & $\begin{array}{l}\text { Ubiquitination/ } \\
\text { degradation }\end{array}$ & $(31)$ \\
\hline Ubal & UBA1 & Q02053 & $\begin{array}{l}\text { Ubiquitin-like modifier- } \\
\text { activating enzyme } 1\end{array}$ & 3.63 & -1.14 & 2 & $\begin{array}{l}\text { Ubiquitination/ } \\
\text { degradation }\end{array}$ & NEW \\
\hline
\end{tabular}

KO: Knockout; WT: wild-type; HCC: hepatocellular carcinoma tissue.

1/1,000; Cell Signaling Technology); monoclonal mouse anti-phosphoc-MYC S62 (dilution 1/500; BioAcademia, Osaka, Japan), rabbit polyclonal anti-phospho-mTOR S2448 (dilution 1/500; Cell Signaling Technology); mouse monoclonal anti-phospho-p70 S6K T389 (dilution 1/1,000; Cell Signaling Technology); and rabbit polyclonal anti-GLI family zinc finger 1 (GLI1) (dilution 1/500; Santa Cruz Biotechnologies). Incubation with horseradish peroxidase-conjugated secundary antibodies (dilution 1/5,000; Cell Signaling Technology) was performed for $1 \mathrm{~h}$ at $4^{\circ} \mathrm{C}$. To visualize the bands, the blots were developed on an ImageQuant LAS 4000 system (GE Healthcare) using Western Bright ECL detection kit (Advansta, San Jose, CA, USA). All densitometric quantifications were carried out with ImageJ software (Imagej.net/ImageJ). An unpaired two-tailed $t$-test was used for statistical analysis and $p$-values below 0.05 were considered significant.

Bioinformatics. The complete dataset of differentially expressed/regulated proteins was loaded into the Ingenuity Pathway Analysis (IPA) software (IPA version 8.7) and database (Ingenuity Systems, Redwood City, CA, USA) to find the most relevant canonical pathways, toxicity pathways or biological functions.

\section{Results}

Histopathological and molecular description of murine liver samples used for proteomics analysis. Four independent HCC samples from four randomly chosen Ppp $2 r 5 d \mathrm{KO}$ mice exhibiting spontaneous hepatocarcinogenesis were collected and snap-frozen, together with a non-cancerous sample from the same livers (paired analysis). The pathological state of the frozen samples, side-by-side with a paraformaldehyde-fixed and hematoxylin/eosin-stained sample of the same tissues (Figure 1A), was confirmed by an experienced liver pathologist. Normal liver tissues from four age- and gendermatched WT mice $(19 \mathrm{~m}, 21 \mathrm{~m}, 22 \mathrm{~m}$ and $23 \mathrm{~m})$ were additionally collected as reference tissues. Although ranging from well- to poorly differentiated, all HCC samples showed increased c-MYC Ser62 phosphorylation, but differed in the activation of other oncogenic pathways, including MEK/ERK, mTOR/p70 S6K and Hedgehog signaling, as previously reported (36) (Figure 1B). One HCC sample showed 'pale body'-like structures of unknown significance (Figure 1A).

Comparative 2D-DIGE analysis. We next generated proteinexpression profiles of the protein lysates of these WT liver $(n=4)$, KO HCC $(n=4)$ and KO non-tumor tissues $(n=4)$ using 2D-DIGE. For this purpose, an internal standard was created, in which $25 \mu \mathrm{g}$ of each lysate $(\mathrm{n}=12)$ was mixed, and labelled with Cy2. Two WT, two KO tumor and two KO non-tumor tissue lysates were labelled with $\mathrm{Cy} 3$; the remaining two WT, 
A

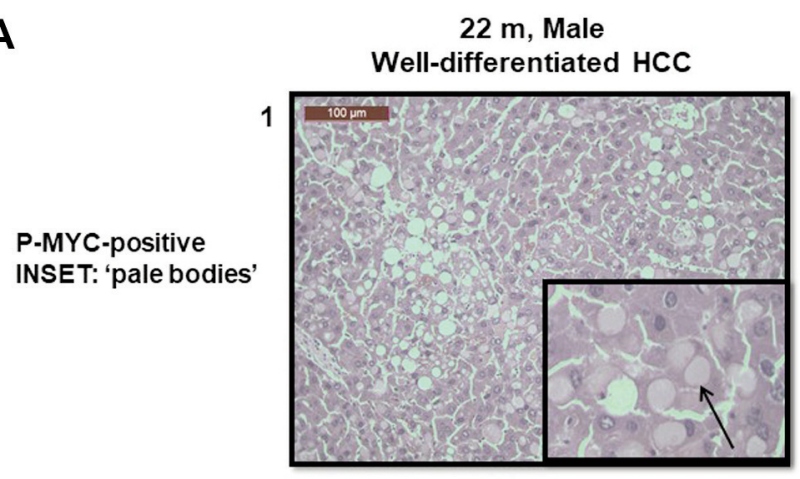

2

P-MYC-positive P-MEK/P-ERK-positive P-p70 s6K-positive P-mTOR-positive

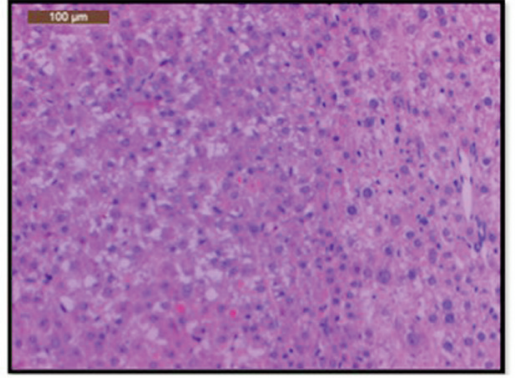

$18 \mathrm{~m}$, Male

Well-differentiated HCC
$22 \mathrm{~m}$, Male

Poorly differentiated HCC, metastasized to lymph nodes
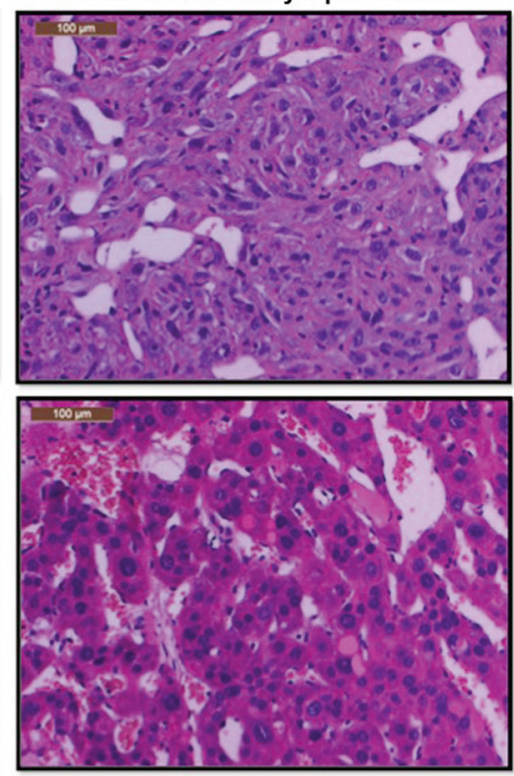

$24 \mathrm{~m}$, Male

Moderately differentiated HCC
3

P-MYC-positive

GLI1/Hedgehog-positive
P-MYC-positive

P-MEK/P-ERK-positive

P-p70 S6K-positive

B
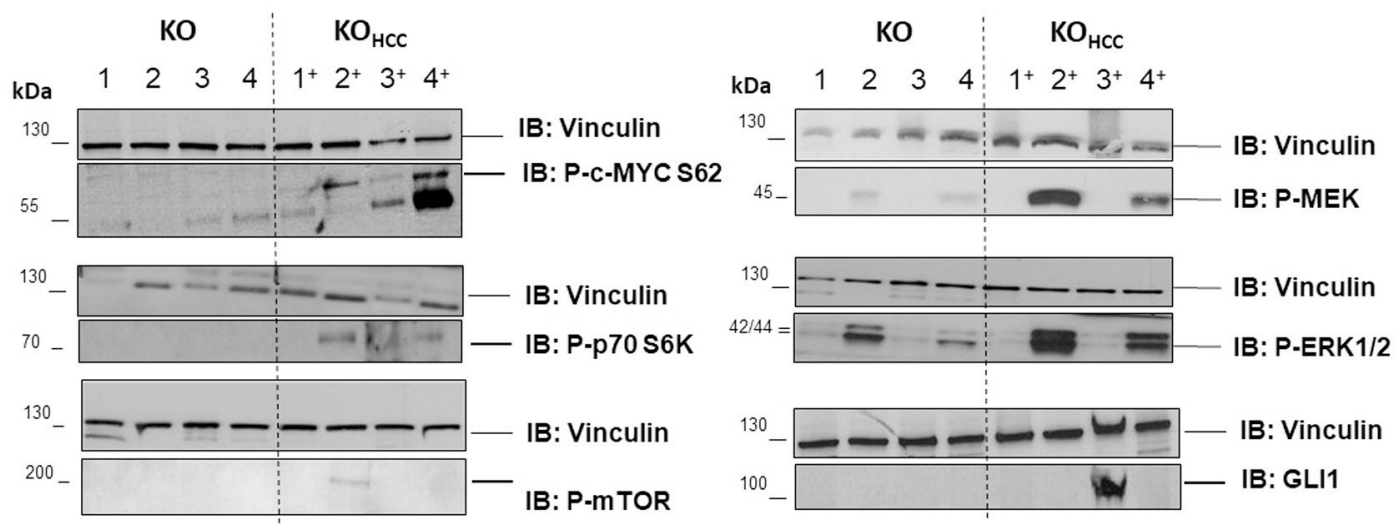

Figure 1. Histopathology of murine protein phosphatase 2 A regulatory subunit B56 $($ Ppp2r5d) knockout (KO) hepatocellular carcinoma (HCC) samples used for proteomics analysis. A: Hematoxylin/eosin-stained sections of the analyzed HCC tissues $(n=4)$ were evaluated by an experienced liver pathologist, and diagnosed as well-differentiated (samples 1 and 2), moderately differentiated (sample 4) and poorly differentiated (sample 3). The latter tumor had been metastasized to the lymph nodes and was positive for expression of the GLI family zinc finger 1 (GLI1) Hedgehog signaling transcription factor. Sample 1 showed 'pale bodies (arrow in inset) of unknown significance. All scale bars: 100 um. B. Immunoblotting analysis with indicated antibodies of the upper HCC samples and adjacent non-cancerous liver samples of the same mice (paired analysis) showed sporadic activation of MAP-extracellular signal-regulated kinase (MEK)/extracellular signal-regulated kinase (ERK), mammalian target of rapamycin ( $m T O R) / p 70$ ribosomal protein S6 kinase ( $p 70 \mathrm{~S} 6 \mathrm{~K})$ and Hedgehog signaling, while c-MYC S62 phosphorylation was up-regulated in all HCC samples analyzed.

two KO tumor and two KO non-tumor lysates were labelled with Cy5. By normalizing the Cy3 or Cy5 intensities to the Cy2 control, it was possible to compensate for gel-to-gel variations. Direct comparison between $\mathrm{Cy} 3$ and $\mathrm{Cy} 5$ spot intensities allowed identification of differentially expressed or regulated proteins. All samples were first resolved on six gels with isoelectric focusing in $\mathrm{pH}$ range 4-7, and then rerun on another six gels with isoelectric focusing in $\mathrm{pH}$ range 
6-9. In $\mathrm{pH}$ range 4-7, 22 differentially expressed spots were detected between WT and non-cancerous KO liver samples $(p<0.05)$, and 154 differentially expressed spots were identified between $\mathrm{KO} \mathrm{HCC}$ and $\mathrm{KO}$ non-tumor tissue $(p<0.05)$ (Figure 2A). In $\mathrm{pH}$ range 6-9, seven spots for differentially expressed proteins between WT and noncancerous $\mathrm{KO}$ livers were found $(p<0.05)$, while 58 were identified between $\mathrm{KO} \mathrm{HCC}$ and $\mathrm{KO}$ non-tumor tissue $(p<0.05)$ (Figure 2A). Representative examples of the analysis of spots that were up-regulated and down-regulated, respectively, in KO HCC are shown (Figure 2B).

MS-based protein identification. Subsequent MS analysis by MALDI TOF/TOF of the spots of differentially regulated proteins eventually resulted in the identification of 129 differentially expressed proteins between either or both conditions (Table I). Twenty proteins were down-regulated in non-tumor KO compared with WT livers, while only three proteins were up-regulated in non-tumor KO versus WT livers. Moreover, the fold-changes in expression between these samples were relatively small, ranging between 1.17to 1.46-fold down-regulation, and between 1.66- to 1.71-fold up-regulation (Table I).

In contrast, many more proteins were found to be differentially expressed between $\mathrm{KO} \mathrm{HCC}$ and $\mathrm{KO}$ non-tumor samples, with much higher absolute differences: 43 were down-regulated in the tumors (range $=1.1$ - to 5.74-fold), while 80 proteins were up-regulated in the tumors (range $=1.43$ - to 35.28-fold) (Table I). Interestingly, four proteins (tubulin alpha-1A chain, METK1, regucalcin and serotransferrin) showed apparently conflicting differential expression patterns in HCC versus non-tumor KO tissues, as they were found to be both up-regulated as well as down-regulated in the tumors (Table I). This might imply they may actually occur as different protein isoforms, for instance due to differing posttranslational modifications or protein processing events. Hence, a total of 119 proteins showed different expression or regulation in normal KO liver versus $\mathrm{HCC}$ KO liver, and were denoted as 'cancer proteins'. Based on Gene Ontology (GO) annotations, these cancer proteins can be grouped into 14 functional classes, covering a wide spectrum of biological functions (Table I and Figure 3). Notably, almost one-quarter of the cancer proteins (23\%) belonged to 'liver metabolism' $(n=22)$ or 'glucose metabolism' $(n=6)$, and appeared mostly to be down-regulated in the tumors, consistent with a degree of hepatocyte de-differentiation and altered cancer cell metabolism. Another $18 \%$ of the cancer proteins were functionally associated with 'mitochondria' (mostly downregulated in the tumors), and 15\% with 'cytoskeleton' (mostly up-regulated in the tumors). Other functional classes were related to 'cell cycle', 'endoplasmic reticulum/protein folding', 'lipid metabolism', 'mRNA processing/translation', 'transport' and 'protein ubiquitination/degradation (all predominantly up- regulated in the tumors) (Figure 3). Interestingly, 66 (56\%) cancer proteins had previously been identified in other proteomic studies of HCC samples from patients, mice or rats (Table I, last column), while the remaining 55 (44\%) others may represent potentially new HCC biomarkers (Table I, last column, 'NEW'). Four proteins of the latter group had however been reported as differentially regulated in HCC in at least one other study, but in the opposite direction of what we found here, potentially testifying once more to the presence of differentially modified proteins rather than differential expression (Table I, last column, 'conflict').

Comparison between 'cancer proteins' and 'cancer genes'. We compared the differentially expressed proteins between $\mathrm{KO}$ $\mathrm{HCC}$ and $\mathrm{KO}$ non-cancerous samples identified here with the differentially expressed genes previously determined by RNAseq analysis in a similar set of Ppp2r5d KO mouse samples (36). Intriguingly, we found the overlap between both datasets was overall rather poor: of 29 differentially expressed genes between WT and KO samples (36), none overlapped with the 23 differentially regulated proteins identified here; and, of 351 differentially expressed genes between $\mathrm{KO}$ nontumor and KO HCC samples (36), only 14 were also retrieved in the list of 119 differentially regulated proteins (Figure 4). For these 14 genes/proteins, the changes in expression were fully concordant at the mRNA and the protein level.

IPA-assisted pathway analysis of differentially regulated proteins. The cancer protein dataset was subsequently loaded into the IPA software and database (IPA; Ingenuity Systems) to identify links with the most relevant functional pathways or altered molecular networks. Importantly, the results confirm the diagnosis of HCC at the biochemical level, since 'cancer' and 'gastrointestinal disease' were the two top hits (Figure 5). Within the top altered pathways and molecular/cellular functions, several metabolic pathways were identified, including amino acid metabolism and the urea cycle, and methionine metabolism. Thus, this analysis indirectly confirms the quality and biological relevance of data obtained by the 2D-DIGE proteomics technique.

Validation of select differentially regulated proteins. One of the most up-regulated proteins in the HCCs was fibrinogen gamma (7.28-fold higher versus adjacent non-tumor tissue) (Table I). A closer inspection of the data revealed, however, that this upregulation predominantly occurred in one of the four HCC samples analyzed, coinciding with the appearance of the 'pale body' structures identified during histopathological examination (Figure 1A). Additional electron microscopy examination of the 'pale bodies' showed rounded dilated cisternae of the rough endoplasmatic reticulum (RER), containing amorphous, granular material (Figure 6A), most likely representing fibrinogen deposits. Fibrinogen is a protein 
A

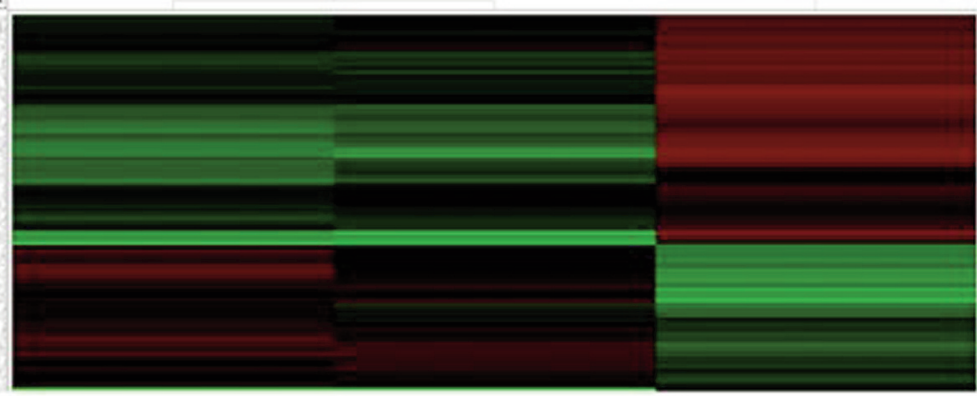

$\mathrm{pH}$ 4-7

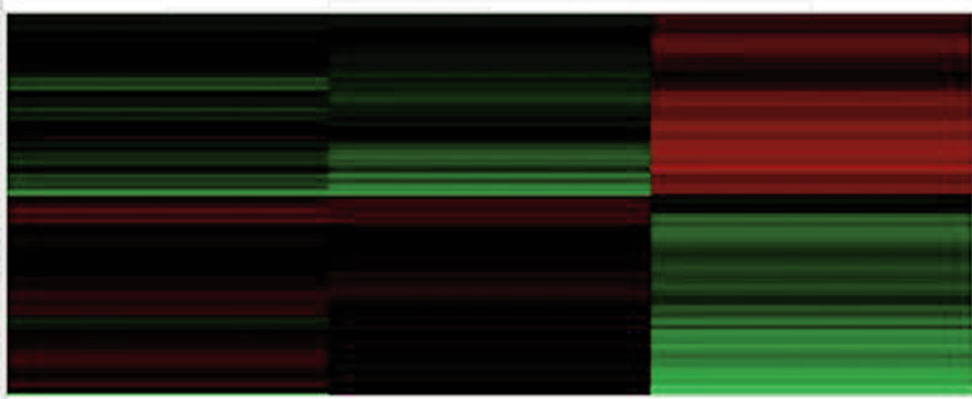

$\mathrm{pH} 6-9$

KO Normal WT Normal KO HCC

B
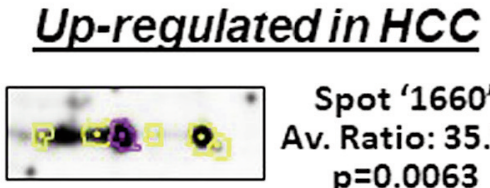

Spot ' 1660 '

Av. Ratio: 35.28

$p=0.0063$

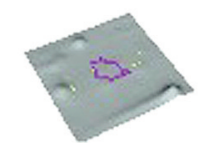

KO normal

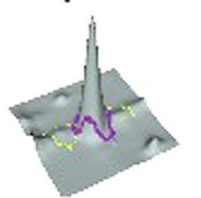

KO HCC

\section{Down-regulated in $\mathrm{HCC}$}

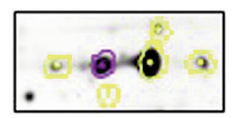

Spot ' 1330 '

Av. Ratio: -5.74

$p=0.014$

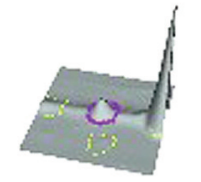

KO normal

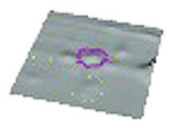

KO HCC
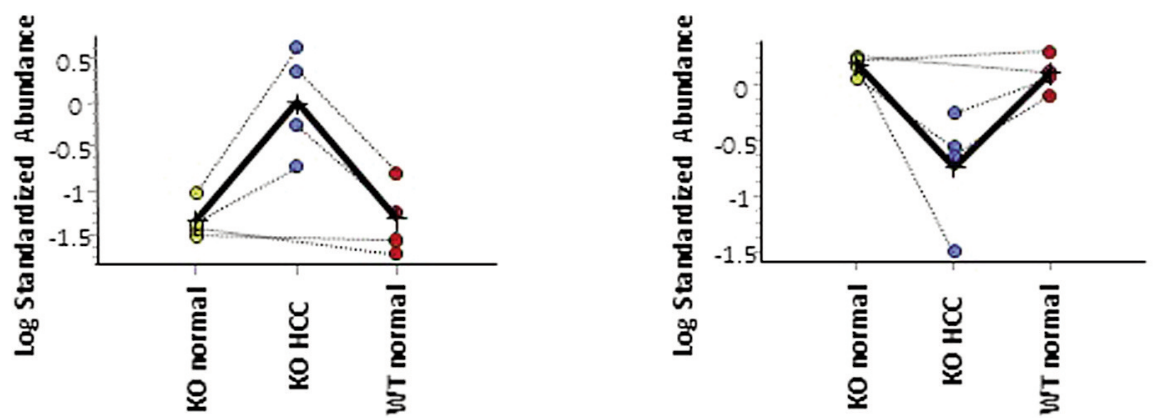

Figure 2. Analysis of differentially regulated spots following two-dimensional differential gel electrophoresis (2D-DIGE) A: Cluster analysis of differentially regulated 'spots' between wild-type (WT), protein phosphatase 2 A regulatory B56 subunit (Ppp2r5d) knockout (KO) non-cancerous, and Ppp2r5d KO hepatocellular carcinoma (HCC) liver tissue, grouped by pH range. Red: up-regulated; green: down-regulated. B: Examples of spot picking and analysis using DeCyder V 7.0 software, for typically up-regulated (left) and down-regulated (right) spots in the KO HCC samples. Proteins in spots were accepted as being differentially expressed when showing a statistically significant $(p<0.05)$ increase or decrease when compared to the control in at least $75 \%$ of the spot maps. 


\section{Up-regulated Down-regulated}

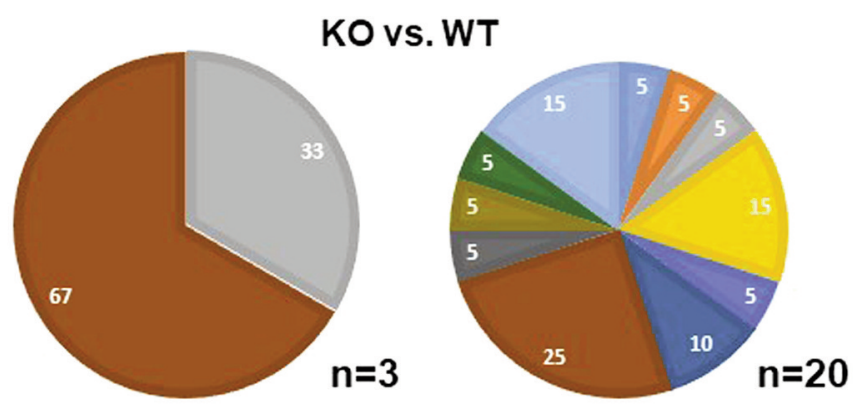

COLOR LEGEND:
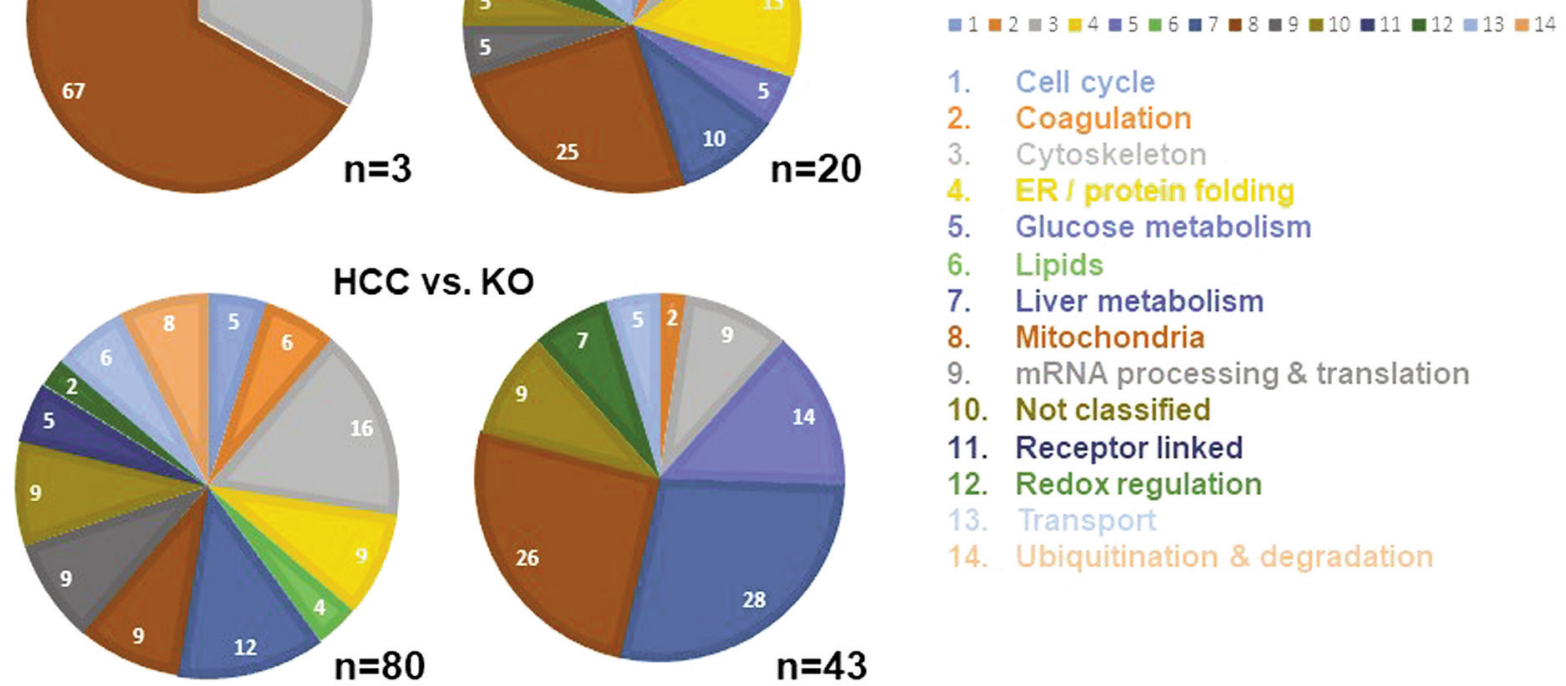

Figure 3. Overview of differentially regulated proteins, grouped into 14 functional classes based on Gene Ontology (GO) annotation. n: Absolute number of up-regulated or down-regulated proteins found; the numbers within the diagrams indicate percentages. In the hepatocellular carcinoma (HCC) samples, the most frequently altered proteins belonged to liver metabolism (28\% of those down-regulated in HCC, and $12 \%$ of those upregulated in $\mathrm{HCC}$ ), mitochondria (26\% of those down-regulated in HCC, and 9\% of those up-regulated in HCC), glucose metabolism (14\% of those down-regulated in $\mathrm{HCC}$ ) and cytoskeleton (16\% of those up-regulated in HCC, and $9 \%$ of those down-regulated in HCC).

synthesized exclusively by hepatocytes, and the intracellular deposition might reflect an impairment in its transport and/or secretion. Interestingly, such fibrinogen deposits have also been reported in human HCCs in 5-5.7\% of cases, depending on the study $(47,48)$. In the B56 $\mathrm{KO}$ mice, the overall incidence of pale body occurrence was $12 \%(3 / 25, n=25)$ (Figure $6 \mathrm{~B})$, matching well with the human HCC data.

Additional validation of the differential proteomics results was performed by western blot analysis of a select number of identified proteins for which antibodies were available. Consistent with the 2D-DIGE results (Table I), downregulation of FBP1 was observed in all HCC samples (Figure 6C). Interestingly, this protein is also down-regulated in human HCC and was suggested to be one of five potential HCC biomarkers identified from a meta-analysis of several proteomic HCC profiling studies (49). In contrast, the slightly increased expression of the PP2A scaffolding A subunit (Table I) was not confirmed by immunoblotting (Figure 6C), suggesting it might rather represent a difference in post-translational modification of this protein. Supporting this hypothesis is another 2D-DIGE study which identified an opposite change in PP2A A subunit expression in HCC, i.e. down-regulation, neither confirming this by western blotting (25). Immunoblots further confirmed the downregulation of phosphoglucomutase-2 (PGM2) (Figure 6C). For $S$-adenosyl methionine synthase 1 (METK1), immunblots confirmed significant down-regulation (Figure 6C), in concordance with the mRNA expression data (Figure 4). However, the 2D-DIGE data additionally identified a spot of this protein significantly up-regulated in the HCCs (7.28fold, $p>0.05$; Table I), suggestive of potential posttranslational modification(s) of METK1 in the tumors.

\section{Discussion}

Genomic and mRNA analyses of human and mouse HCC have revealed significant overlaps between chromosomal aberrations and gene-expression signatures (50). However, because proteins rather than mRNA are the major effectors of cellular and tissue functions, complementary comparative analyses at the proteome level are equally important in gaining insights into the mechanisms of hepatocarcinogenesis 


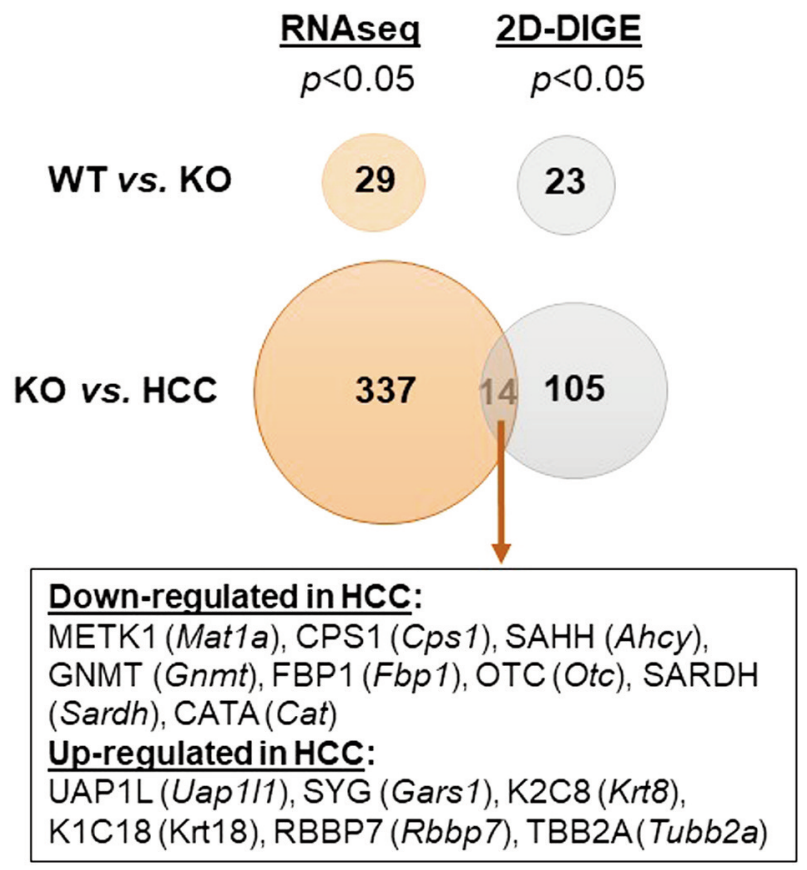

Figure 4. Comparison between the number of differentially expressed mRNAs as determined by RNAseq (36) and as identified in the current study. While there was no overlap between both datasets in the livers from wild-type (WT) vs. non-cancerous knockout (KO) mice, 14 genes/proteins appeared to be commonly regulated at the $\mathrm{MRNA}$ and protein levels in the non-cancerous KO livers vs. the KO HCCs. The identities of these 'cancer' genes/proteins are detailed in the box.

\section{IPA Summary of Analysis}

\begin{tabular}{|c|c|c|c|c|}
\hline \multicolumn{4}{|c|}{ Top networks } & score: \\
\hline 1 & \multicolumn{3}{|c|}{ Small molecule biochemistry, cancer, reproductive system disease } & 55 \\
\hline 2 & \multicolumn{3}{|c|}{ Immunological disease, hematological disease, inflammatory disease } & 46 \\
\hline 3 & \multicolumn{3}{|c|}{ Cellular compromise, organismal injury, abnormalities lipid metabolism } & 23 \\
\hline 4 & \multicolumn{3}{|c|}{ Lipid metabolism, molecular transport, small molecule biochemistry } & 23 \\
\hline 5 & \multicolumn{3}{|c|}{ Cell death, tumor morphology, cell-to-cell signaling and interaction } & \\
\hline \multicolumn{3}{|c|}{ Top bio functions } & \multicolumn{2}{|c|}{ number of molecules } \\
\hline & \multicolumn{4}{|c|}{ Diseases and disorders } \\
\hline & & Cancer & \multicolumn{2}{|c|}{$38(1.7 E-09-3.0 E-02)$} \\
\hline & & Gastrointestinal disease & \multicolumn{2}{|c|}{$22(1.7 \mathrm{E}-09-3.0 \mathrm{E}-02)$} \\
\hline & & Hematological disease & \multicolumn{2}{|c|}{$22(2.5 E-09-2.5 E-02)$} \\
\hline & & Immunological disease & \multicolumn{2}{|c|}{$23(5.3 E-08-2.6 E-02)$} \\
\hline & & Inflammatory disease & \multicolumn{2}{|c|}{$30(6.7 \mathrm{E}-08-2.6 \mathrm{E}-02)$} \\
\hline & \multicolumn{4}{|c|}{ Molecular and cellular functions } \\
\hline & & Small molecule biochemistry & \multicolumn{2}{|c|}{$31(5.8 E-08-3.3 E-02)$} \\
\hline & & Amino acid metabolism & \multicolumn{2}{|c|}{$11(1.9 \mathrm{E}-06-2.5 \mathrm{E}-02)$} \\
\hline & 3 & Cellular assembly and organization & \multicolumn{2}{|c|}{$15(1.7 E-05-2.9 E-02)$} \\
\hline & 4 & Cell morphology & \multicolumn{2}{|c|}{$8(5.2 \mathrm{E}-05-3.2 \mathrm{E}-02)$} \\
\hline & 5 & Post-translational modification & \multicolumn{2}{|c|}{$13(5.2 \mathrm{E}-05-2.9 \mathrm{E}-02)$} \\
\hline & \multicolumn{4}{|c|}{ Physiological system development and function } \\
\hline & & Ha ir and skin development and function & \multicolumn{2}{|c|}{$4(1.7 \mathrm{E}-05-2.1 \mathrm{E}-02)$} \\
\hline & 2 & Organismal development & \multicolumn{2}{|c|}{$9(1.7 \mathrm{E}-05-3.1 \mathrm{E}-02)$} \\
\hline & & Hepatic system development and function & \multicolumn{2}{|c|}{$2(5.2 E-05-3.0 E-02)$} \\
\hline & & Endocrine system development and function & \multicolumn{2}{|c|}{$2(1.0 \mathrm{E}-04-2.5 \mathrm{E}-02)$} \\
\hline & 5 & Tissue development & \multicolumn{2}{|c|}{$11(7.2 \mathrm{E}-04-3.3 \mathrm{E}-02)$} \\
\hline \multicolumn{3}{|c|}{ Top canonical pathways } & \multicolumn{2}{|r|}{$p$-Value: } \\
\hline 1 & \multicolumn{2}{|c|}{ Acute phase response signaling } & \multicolumn{2}{|r|}{ 7.70E-05 } \\
\hline 2 & \multicolumn{3}{|c|}{ 14-3-3 Mediated signaling } & 1.14E-04 \\
\hline 3 & Urea & cycle and metabolism of a mino groups & & 1.23E-04 \\
\hline 4 & Brea & ist cancer regulation by stathmin 1 & & $1.22 \mathrm{E}-03$ \\
\hline 5 & Met! & hionine metabolism & & $1.49 \mathrm{E}-03$ \\
\hline
\end{tabular}

Figure 5. In silico pathway analysis of 'cancer proteins'. Ingenuity Pathway Analysis (IPA) of 119 proteins differentially regulated between knockout (KO) hepatocellular carcinoma (HCC) and non-cancerous KO livers, with indication of Top networks, bio-functions and canonical pathways. and to discover novel prognostic or predictive markers for improved HCC (targeted) treatment. Here, we used 2D-DIGE to identify changes between the proteome of spontaneous HCCs in Ppp2r5d KO mice, their surrounding non-tumoral tissue and normal WT liver tissue. We identified 23 proteins differentially expressed or regulated between normal WT and KO livers, and 119 proteins differentially expressed or regulated between KO HCC and normal KO livers (the latter defined as 'cancer proteins'). Intriguingly, the overlap with our previously published transcriptomics data, performed on mRNA isolated from similar tissue samples, was very poor, with only 14 proteins/mRNAs commonly found differentially expressed between $\mathrm{KO} \mathrm{HCC}$ and non-tumor $\mathrm{KO}$ tissue, and thus, only $12 \%$ of the cancer proteins concordantly regulated at the mRNA level. It is known that proteins with very high or very low $\mathrm{pI}$ as well as hydrophobic proteins are in general more difficult to detect by 2D-DIGE, and that there is some bias in favor of cytoplasmic and soluble proteins (18). Moreover, 2D-DIGE is definitely biased towards the identification of medium to highly abundant proteins and does not provide a comprehensive nor representative view of the tissue proteome. On the other hand, a change in mRNA level does not always reflect a corresponding change in protein level, especially for proteins with a low turnover. Finally, an obvious difference in protein expression as identified by 2D-DIGE may actually also represent expression of an altered isoform, post-translationally modified or processed form of the protein, which cannot be detected by RNAseq analysis. This all illustrates the complementarity of transcriptomic and proteomic analyses.

Unbiased IPA analysis of the cancer proteins identified 'gastrointestinal disease' and 'cancer' as the top hits, independently confirming the diagnosis of our samples and hence, indirectly, the quality of the data obtained. In addition, within the cancer proteins, several established HCC biomarkers or differentially expressed proteins identified in former 2DDIGE studies of human, rat or mouse HCC samples were confirmed (56\%) (Table I, indicated in bold), further testifying to the data quality and suitability of the model.

When looking in more detail at the list of cancer proteins, an obvious finding is the overt decrease in 'metabolism'associated proteins in the Ppp2r5d KO HCCs, both in 
A
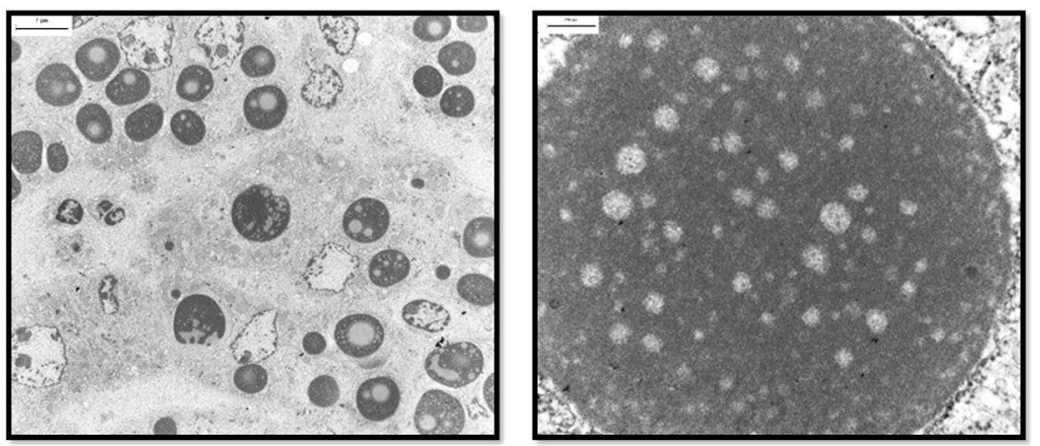

B $\square \mathrm{HCC} \quad \mathrm{HCC}+$ Fibrinogen

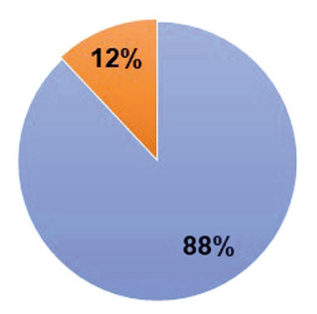

C
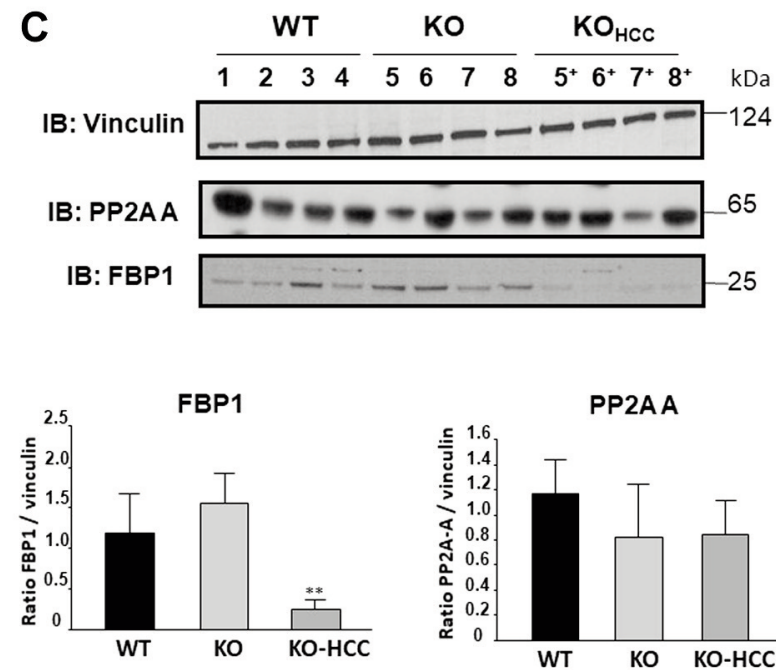

PP2AA

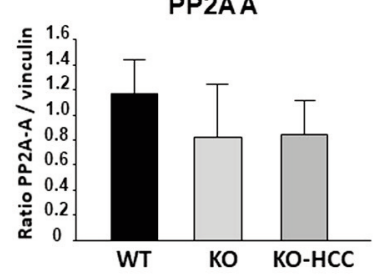

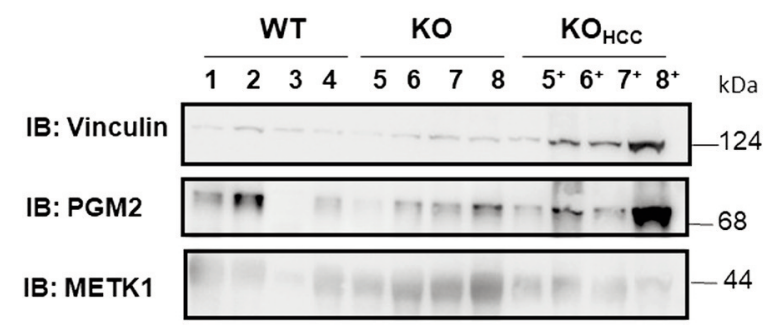

PGM2

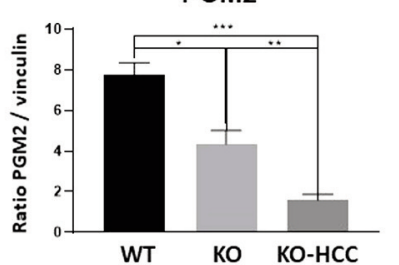

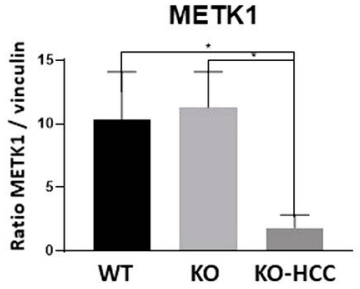

Figure 6. Validation of two-dimensional differential gel electrophoresis (2D-DIGE) results. A: Additional analysis of 'pale body' structures by electron microscopy. B: Frequency of occurrence of fibrinogen deposits in hepatocellular carcinomas (HCCs) from protein phosphatase $2 A$ (PP2A) regulatory B56 subunit (Ppp2r5d) knockout (KO) mice. Total number of hepatocellular carcinomas (HCCs) analyzed was 25. C: Validation of differentially expressed/regulated proteins by immunoblotting. FBP1 (fructose-1,6-bisphosphatase 1): 4.7-fold less expression in HCC compared to wild-type (WT) ( $p=0.015)$ and 6.2-fold less expression compared to non-tumor KO ( $p=0.002)$. PP2A scaffolding A subunit: no significant differences in expression between HCC, non-tumor KO or WT ( $p>0.05)$. Phosphoglucomutase-2 (PGM2): 5.5-fold less expression in HCC compared to WT $(p=0.0001)$ and 3.3-fold less expression compared to non-tumor KO ( $p=0.0086)$. S-Adenosylmethionine synthase 1 (METK1): 5.7-fold less expression in HCC compared to WT $(p=0.049)$ and 6.1-fold less expression compared to non-tumor KO $(p=0.019)$.

proteins classified as belonging to 'glucose metabolism' as 'liver metabolism' - not only testifying to significant metabolic changes in the cancer cells, but likely also to a degree of de-differentiation of the hepatocytes. Downregulation of Fbpl (an enzyme promoting gluconeogenesis), seen at the mRNA level as well (Figure 4) and confirmed by immunoblotting (Figure 6B), suggests changes in glucose metabolism consistent with the Warburg effect (a change from oxidative phosphorylation to aerobic glycolysis) (51). Several enzymes involved in protein and amino acid degradation [e.g. phenylalanine-4-hydroxylase (PH4H), mitochondrial acetyl-CoA acetyltransferase (THIL), cytoplasmic malate dehydrogenase (MDHC)] were also reduced, while proteins involved in glutamine (a critical amino acid for proliferation of tumor cells) synthesis were up-regulated [e.g. ornithine aminotransferase (OAT)] as well as proteins involved in protein translation in general [e.g. eukaryotic translation initiation factor 4B (IF4B), 60S acidic ribosomal protein P0 (RLA0), histidyl-tRNA synthetase (SYHC), glycyl-tRNA synthetase (SYG), ribosome biogenesis protein WDR12 (WDR12)] and in protein maturation processing [e.g. methionine aminopeptidase $1 \mathrm{D}$ (AMP1D), protein disulfide-isomerase (PDIA1), protein disulfide-isomerase A3 (PDIA3)] (Table I). The urea cycle seemed significantly impaired in the HCCs [e.g. downregulation of carbamoyl-phosphate synthase (CPS1) and 
ornithine carbamoyl transferase (OTC)] as was the liver methylation cycle, with four essential enzymes in this process, METK1, glycine $N$-methyl transferase (GNMT), betaine-homocysteine- $S$-methyl transferase 1 (BHMT1) and adenosyl homocysteinase (SAHH), all being down-regulated (Table I). Down-regulation of METK1, validated by our immunoblotting results (Figure 6B), and down-regulation of SAHH and GNMT are likely caused by reduced gene expression, as Matla, Ahcy and Gnmt mRNAs were also found to be reduced in the 'cancer genes' list (Figure 4) (36). Interestingly, however, we also found METK1 to be significantly up-regulated in a different spot (Table I), likely testifying from a different post-translationally modified form or different isoform, being specifically increased in the HCCs. Such explanation would also reconcile seemingly contradicting data in literature, describing METK1 upregulation $(12,31)$, as well as down-regulation in $\mathrm{HCC}(13$, 14). In any case, down-regulation of the methylation cycle and, hence, chronic $S$-adenosyl-L-methionine deficiency, have been shown to result in spontaneous HCC development in Matla and Gnmt KO mice $(52,53)$, which our data are fully consistent with.

A similar explanation may hold true for tubulin alpha-1A chain (TBA1A), serotransferrin (TRFE) and regucalcin (RGN), which we and others (Table I) identified in inversely altered spots, seemingly both up-regulated and downregulated in HCC. RGN is a senescence marker, suppresses HCC growth in vitro $(54,55)$ and its expression is correlated with improved survival of patients with HCC (54), suggesting it is likely expressed less in the Ppp $2 r 5 d$ KO HCCs, while the spot of up-regulated protein may represent a modified form. In contrast, TBA1A is a cytoskeletal protein that was likely up-regulated in the Ppp2r5d KO HCCs, as was the case for at least three other members of the tubulin family that were differentially regulated in our dataset (TBB2A, TBB2B, TBB5; Table I); and TBB2A also at the mRNA level (Figure 4) alongside several other cytoskeleton proteins (different cytokeratins, desmin and vimentin). Vimentin is known to be abundantly expressed in human HCC and its overexpression is significantly associated with HCC metastasis (56). Likewise, expression levels of cytokeratin 8 (K2C8) have been positively correlated with HCC metastatic ability (57), and this up-regulation apparently occurs at the mRNA level (Figure 4). Together with serum albumin and apolipoprotein A1, serotransferrin was amongst the most highly upregulated proteins in the cancer protein list. We suggest that the huge increase of these proteins in HCCs might actually represent accumulation of extravascular plasma protein in the tumor microenvironment, and not necessarily increased protein synthesis by the tumor cells. Increased serotransferrin levels in that environment might additionally induce transferrin-mediated iron uptake, thereby satisfying the high iron demand of the highly proliferating cancer cells. The spot representing down-regulated serotransferrin may again correspond to an altered post-translationally modified form or transferrin isoform.

Equally highly overexpressed in the HCCs was fibrinogen$\gamma$. Fibrinogen is a protein exclusively synthesized by hepatocytes, and it was specifically found to be overexpressed in one of four HCC samples analyzed, which at the histological level featured 'pale body' structures (Figure 1A), and at the ultrastructural level appeared as dilated cisternae of the RER, filled with amorphous, granular material (Figure $6 \mathrm{~A})$. Since the RER is the site of protein synthesis, and fibrinogen is a secreted protein, its retention in the RER likely represents deficient translocation to the smooth ER or Golgi apparatus, and eventually a defect in fibrinogen transport. Interestingly, such pale bodies are observed in about 5-5.7\% of human HCCs $(47,48)$ and therefore represent another clinical feature of Ppp2r5d (B568) KO HCC that we found in $12 \%$ of our analyzed mouse HCC samples.

The down-regulation of mitochondrial proteins, except mitochondrial heat-shock proteins (HSPs), which were significantly up-regulated, suggest a loss of function of this organelle, with potentially increased stress. The up-regulation of several molecular chaperones [mitochondrial stress-70 protein (GRP75), $78 \mathrm{kDa}$ glucose-regulated protein (GRP78), heat-shock cognate $71 \mathrm{kDa}$ protein (HSP7C) and mitochondrial $60 \mathrm{kDa}$ heat-shock protein $(\mathrm{CH} 60)$ ] has been reported in several HCC studies (Table I), and the overexpression of these proteins may be interpreted as a response to the stressful cancerous environment for cytoprotective functions. Up-regulation of HSPs may also contribute to the tumor cell adaptive response to altered oxygen levels, as testified by altered expression of antioxidant defense enzymes, such as catalase (CATA), glutathione peroxidases (GPX1) and peroxiredoxins (PRDX2) (Table I).

The HCCs also showed an increased protein ubiquitination/degradation signature, with upregulation of proteins belonging to the ubiquitin-mediated degradation machinery [e.g. 26S protease regulatory subunit 6B (PRS6B), 26S protease regulatory subunit 7 (PRS7), 26S proteasome non-ATPase regulatory subunit 13 (PSD13) and proteasome subunit beta type 4 (PSMB4)], as well as of proteins enzymatically regulating the poly-ubiquitination process [e.g. ubiquitin-like modifier-activating enzyme 1 (UBA1)]. Increased ubiquitin immunopositivity has also been observed in human HCC samples, and was predictive for HCC re-occurrence (58).

Thus, as a first conclusion, our study confirmed many of previously found protein HCC biomarkers. Such a successful reproduction of previously reported results clearly underscores the applicability of the approach. Moreover, it demonstrates the suitability of spontaneous HCC development in Ppp $2 r 5 d \mathrm{KO}$ mice as a new valuable murine hepatocarcinogenesis model that captures many characteristics of the human disease. 
In addition, however, our study also identified many previously unreported molecules that might theoretically have significant roles in HCC tumorigenesis or progression and become novel HCC biomarkers (Table I, last column, 'NEW'). For us, the most suitable candidates for further validation seem to be the three proteins categorized as 'cell cycle' proteins [coiled-coiled domain protein 15 (CCDC15), protein ELYS (ELYS) and histone-binding protein RBBP7 (RBBP7)], which were all significantly up-regulated in the HCCs (2.51to 4.92-fold); the cytoskeletal protein desmin (3.51-fold upregulated); phosphoglucomutase-2 (PGM2) (2.95-fold downregulated, confirmed by immunoblotting); several liver metabolic enzymes [e.g. adipocyte plasma-membrane associated protein (APMAP) and guanine deaminase (GUAD), 3.44- and 3.09-fold down-regulated); several mitochondrial enzymes, particularly NADH dehydrogenase flavoprotein 2 (35.28-fold up-regulated); eIF4B and WDR12 (up-regulated 2.14- and 2.85-fold); receptor-linked proteins Rab GDP dissociation inhibitor alpha (GDIA), GDIB, V-type protein ATPase catalytic subunit A (VATA) and VATB2 (up-regulated 1.52- to 5.52-fold); thyroglobulin (5.74-fold down-regulated); protein degradation-linked proteins COP9 signalosome complex subunit 4 (CSN4), UBA1 and PRS6B (4-, 3.63- and 3.69-fold up-regulated); and some 'unclassified proteins' (e.g. histone acetyltransferase MYST3, 3-fold up-regulated). Further validation and investigation of these proteins in human HCC samples may eventually result in the discovery of new molecular targets for therapy, or biomarkers for early detection or prognosis.

\section{Conflicts of Interest}

The Authors have no conflicts of interest to declare.

\section{Authors' Contributions}

C.L. performed all mouse-related experiments, tissue isolation, protein extraction, MS sample preparation and overall data analysis; G.B.F. performed 2D gel electrophoresis and 2D-DIGE-related data analysis (spot picking; clustering); J.D.O. performed and analyzed immunoblot validation experiments; L.L. performed histopathologic analysis of all liver tissues; R.D.V. performed electron microscopy; R.D. analyzed data by IPA software; L.O and C.M. supervised 2DDIGE analysis; E.W. performed MS analysis and data processing (Mascot search and protein identifications); VJ and EW designed and supervised the study, and wrote the article.

\section{Acknowledgements}

Funding was provided by the KU Leuven Research Fund (C24/17/073 to V.J. and R.D.), the Belgian IAP program (P7/13 to V.J. and E.W.), the Research Foundation-Flanders (G.0B01.16N to V.J.; FWO-SB fellowship to J.D.O.) and the Flemish Agency for Innovation by Science and Technology (IWTSB fellowship to C.L.).

\section{References}

1 Torre LA, Bray F, Siegel RL, Ferlay J, Lortet-Tieulent J and Jemal A: Global cancer statistics, 2012. CA Cancer J Clin 65(2): 87-108, 2015. PMID: 25651787. DOI: $10.3322 /$ caac. 21262

2 Llovet JM, Montal R, Sia D and Finn RS: Molecular therapies and precision medicine for hepatocellular carcinoma. Nat Rev Clin Oncol 15(10): 599-616, 2018. PMID: 30061739. DOI: 10.1038/s41571-018-0073-4

3 Bruix J, da Fonseca LG and Reig M: Insights into the success and failure of systemic therapy for hepatocellular carcinoma. Nat Rev Gastroenterol Hepatol 16(10): 617-630, 2019. PMID: 31371809. DOI: $10.1038 / \mathrm{s} 41575-019-0179-\mathrm{x}$

4 Faivre S, Rimassa L and Finn RS: Molecular therapies for HCC: Looking outside the box. J Hepatol 72(2): 342-352, 2020. PMID: 31954496. DOI: 10.1016/j.jhep.2019.09.010

5 Marin JJG, Macias RIR, Monte MJ, Romero MR, Asensio M, Sanchez-Martin A, Cives-Losada C, Temprano AG, EspinosaEscudero R, Reviejo M, Bohorquez LH and Briz O: Molecular bases of drug resistance in hepatocellular carcinoma. Cancers 12(6): 1663, 2020. PMID: 32585893. DOI: 10.3390/cancers 12061663

6 Rebouissou S and Nault JC: Advances in molecular classification and precision oncology in hepatocellular carcinoma. J Hepatol 72(2): 215-229, 2020. PMID: 31954487. DOI: 10.1016/ j.jhep.2019.08.017

7 Sia D, Villanueva A, Friedman SL and Llovet JM: Liver cancer cell of origin, molecular class, and effects on patient prognosis. Gastroenterology 152(4): 745-761, 2017. PMID: 28043904. DOI: 10.1053/j.gastro.2016.11.048

8 Zucman-Rossi J, Vilanueva A, Nault JC and Llovet JM: Genetic landscape and biomarkers of hepatocellular carcinoma. Gastroenterology 149(5): 1226-1239, 2015. PMID: 26099527. DOI: $10.1053 /$ j.gastro.2015.05.061

9 Schulze K, Nault JC and Villanueva A: Genetic profiling of hepatocellular carcinoma using next-generation sequencing. J Hepatol 65(5): 1031-1042, 2016. PMID: 27262756. DOI: 10.1016/j.jhep.2016.05.035

10 Totoki Y, Tatsuno K, Covington KR, Ueda H, Creighton CJ, Kato M, Tsuji S, Donehower LA, Slagle BL, Nakamura H, Yamamoto S, Shinbrot E, Hama N, Lehmkuhl M, Hosoda F, Arai Y, Walker K, Dahdouli M, Gotoh K, Nagae G, Gingras MC, Muzny DM, Ojima H, Shimada K, Midorikawa Y, Goss JA, Cotton R, Hayashi A, Shibahara J, Ishikawa S, Guiteau J, Tanaka M, Urushidate T, Ohashi S, Okada N, Doddapaneni H, Wang M, Zhu Y, Dinh H, Okusaka T, Kokudo N, Kosuge T, Takayama T, Fukayama M, Gibbs RA, Wheeler DA, Aburatani H and Shibata T: Transancestry mutational landscape of hepatocellular carcinoma genomes. Nat Genet 46(12): 1267-1273, 2014. PMID: 25362482. DOI: $10.1038 / \mathrm{ng} .3126$

11 Schulze K, Imbeaud S, Letouzé E, Alexandrov LB, Calderaro J, Rebouissou S, Couchy G, Meiller C, Shinde J, Soysouvanh F, Calatayud AL, Pinyol R, Pelletier L, Balabaud C, Laurent A, Blanc JF, Mazzaferro V, Calvo F, Villanueva A, Nault JC, BioulacSage P, Stratton MR, Llovet JM and Zucman-Rossi J: Exome sequencing of hepatocellular carcinomas identifies new mutational signatures and potential therapeutic targets. Nat Genet 47(5): 505511, 2015. PMID: 25822088. DOI: 10.1038/ng.3252

12 Lee IN, Chen CH, Sheu JC, Lee HS, Huang GT, Yu CY, Lu FJ and Chow LP: Identification of human hepatocellular carcinoma- 
related biomarkers by two-dimensional difference gel electrophoresis and mass spectrometry. J Proteome Res 4(6): 2062-2069, 2005. PMID: 16335951. DOI: 10.1021/pr0502018

13 Liang CR, Leow CK, Neo JC, Tan GS, Lo SL, Lim JW, Seow TK, Lai PB and Chung MC: Proteome analysis of human hepatocellular carcinoma tissues by two-dimensional difference gel electrophoresis and mass spectrometry. Proteomics 5(8): 22582271, 2005. PMID: 15852300. DOI: 10.1002/pmic 200401256

14 Sun W, Xing B, Sun Y, Du X, Lu M, Hao C, Lu Z, Mi W, Wu S, Wei H, Gao X, Zhu Y, Jiang Y, Qian X and He F: Proteome analysis of hepatocellular carcinoma by two-dimensional difference gel electrophoresis: novel protein markers in hepatocellular carcinoma tissues. Mol Cell Proteomics 6(10): 1798-1808, 2007. PMID: 17627933. DOI: 10.1074/mcp.M600449-MCP200

15 Strathmann J, Paal K, Ittrich C, Krause E, Appel KE, Glauert HP, Buchmann A and Schwarz M: Proteome analysis of chemically induced mouse liver tumors with different genotype. Proteomics 7(18): 3318-3331, 2007. PMID: 17722141. DOI: 10.1002/pmic. 200600983

16 Rousseau B, Ménard L, Haurie V, Taras D, Blanc JF, MoreauGaudry F, Metzler P, Hugues M, Boyault S, Lemière S, Canron X, Costet P, Cole M, Balabaud C, Bioulac-Sage P, Zucman-Rossi $\mathrm{J}$ and Rosenbaum J: Overexpression and role of the ATPase and putative DNA helicase RuvB-like 2 in human hepatocellular carcinoma. Hepatology 46(4): 1108-1118, 2007. PMID: 17657734. DOI: $10.1002 /$ hep. 21770

17 Teramoto R, Minagawa H, Honda M, Miyazaki K, Tabuse Y, Kamijo K, Ueda T and Kaneko S: Protein expression profile characteristic to hepatocellular carcinoma revealed by 2D-DIGE with supervised learning. Biochim Biophys Acta 1784(5): 764772, 2008. PMID: 18359300. DOI: 10.1016/j.bbapap.2008.02.011

18 Minagawa H, Yamashita T, Honda M, Tabuse Y, Kamijo K, Tsugita A and Kaneko S: Comparative analysis of proteome and transcriptome in human hepatocellular carcinoma using 2D-DIGE and SAGE. Protein J 27(7-8): 409-419, 2008. PMID: 19048362. DOI: $10.1007 / \mathrm{s} 10930-007-9123-y$

19 Chafey P, Finzi L, Boisgard R, Caüzac M, Clary G, Broussard C, Pégorier JP, Guillonneau F, Mayeux P, Camoin L, Tavitian B, Colnot $\mathrm{S}$ and Perret $\mathrm{C}$ : Proteomic analysis of beta-catenin activation in mouse liver by DIGE analysis identifies glucose metabolism as a new target of the Wnt pathway. Proteomics 9(15): 3889-3900, 2009. PMID: 19639598. DOI: 10.1002/pmic.200800609

20 Corona G, De Lorenzo E, Elia C, Simula MP, Avellini C, Baccarani U, Lupo F, Tiribelli C, Colombatti A and Toffoli G: Differential proteomic analysis of hepatocellular carcinoma. Int J Oncol 36(1): 93-99, 2010. PMID: 19956837.

21 Liu Y, Li C, Xing Z, Yuan X, Wu Y, Xu M, Tu K, Li Q, Wu C, Zhao $\mathrm{M}$ and Zeng R: Proteomic mining in the dysplastic liver of WHV/cMYC mice-insights and indicators for early hepatocarcinogenesis. FEBS J 277(19): 4039-4053, 2010. PMID: 20807235. DOI: 10.1111/j.1742-4658.2010.07795.x

22 Albrethsen J, Miller LM, Novikoff PM and Angeletti RH: Gelbased proteomics of liver cancer progression in rat. Biochim Biophys Acta 1814(10): 1367-1376, 2011. PMID: 21683810. DOI: 10.1016/j.bbapap.2011.05.018

23 Codarin E, Renzone G, Poz A, Avellini C, Baccarani U, Lupo F, di Maso V, Crocè SL, Tiribelli C, Arena S, Quadrifoglio F, Scaloni A and Tell G: Differential proteomic analysis of subfractioned human hepatocellular carcinoma tissues. J Proteome Res 8(5): 2273-2284, 2009. PMID: 19290626. DOI: 10.1021/pr8009275
24 Matos JM, Witzmann FA, Cummings OW and Schmidt CM: A pilot study of proteomic profiles of human hepatocellular carcinoma in the United States. J Surg Res 155(2): 237-243, 2009. PMID: 19535095. DOI: $10.1016 /$ j.jss.2008.06.008

25 Ritorto MS and Borlak J: Combined serum and tissue proteomic study applied to a c-MYC transgenic mouse model of hepatocellular carcinoma identified novel disease regulated proteins suitable for diagnosis and therapeutic intervention strategies. J Proteome Res 10(7): 3012-3030, 2011. PMID: 21644509. DOI: $10.1021 / \mathrm{pr} 101207 \mathrm{t}$

26 Megger DA, Bracht T, Kohl M, Ahrens M, Naboulsi W, Weber F, Hoffmann AC, Stephan C, Kuhlmann K, Eisenacher M, Schlaak JF, Baba HA, Meyer HE and Sitek B: Proteomic differences between hepatocellular carcinoma and nontumorous liver tissue investigated by a combined gel-based and label-free quantitative proteomics study. Mol Cell Proteomics 12(7): 2006-2020, 2013. PMID: 23462207. DOI: 10.1074/mcp.M113.028027

27 Kimura K, Ojima H, Kubota D, Sakumoto M, Nakamura Y, Tomonaga T, Kosuge T and Kondo T: Proteomic identification of the macrophage-capping protein as a protein contributing to the malignant features of hepatocellular carcinoma. J Proteomics 78: 362-373, 2013. PMID: 23085225. DOI: 10.1016/j.jprot. 2012.10.004

28 Tan GS, Lim KH, Tan HT, Khoo ML, Tan SH, Toh HC and Chung MCM: Novel proteomic biomarker panel for prediction of aggressive metastatic hepatocellular carcinoma relapse in surgically resectable patients. J Proteome Res 13(11): 4833-4846, 2014. PMID: 24946162. DOI: 10.1021/pr500229n

29 Reis H, Padden J, Ahrens M, Pütter C, Bertram S, Pott LL, Reis AC, Weber F, Juntermanns B, Hoffmann AC, Eisenacher M, Schlaak JF, Canbay A, Meyer HE, Sitek B and Baba HA: Differential proteomic and tissue expression analyses identify valuable diagnostic biomarkers of hepatocellular differentiation and hepatoid adenocarcinomas. Pathology 47(6): 543-550, 2015. PMID: 26308133. DOI: 10.1097/PAT.0000000000000298

30 Jin B, Gong Z, Yang N, Huang Z, Zeng S, Chen H, Hu S and Pan G: Downregulation of betaine homocysteine methyltransferase (BHMT) in hepatocellular carcinoma associates with poor prognosis. Tumour Biol 37(5): 5911-5917, 2016. PMID: 26592251. DOI: 10.1007/s13277-015-4443-6

31 Rong Z, Fan T, Li H, Li J, Wang K, Wang X, Dong J, Chen J, Wang F, Wang J and Wang A: Differential proteomic analysis of gender-dependent hepatic tumorigenesis in Hras $12 \mathrm{~V}$ transgenic mice. Mol Cell Proteomics 16(8): 1475-1490, 2017. PMID: 28512230. DOI: 10.1074/mcp.M116.065474

32 Zubaidah RM, Tan GS, Tan SBE, Lim SG, Lin Q and Chung MCM: 2-D DIGE profiling of hepatocellular carcinoma tissues identified isoforms of far upstream binding protein (FUBP) as novel candidates in liver carcinogenesis. Proteomics 8(23-24): 5086-5096, 2008. PMID: 19003864. DOI: 10.1002/pmic.200800322

33 Megger DA, Rosowski K, Ahrens M, Bracht T, Eisenacher M, Schlaak JF, Weber F, Hoffmann AC, Meyer HE, Baba HA and Sitek B: Tissue-based quantitative proteome analysis of human hepatocellular carcinoma using tandem mass tags. Biomarkers 22(2): 113-122, 2017. PMID: 27467182. DOI: $10.1080 / 135475$ 0X.2016.1210678

34 Heindryckx F, Colle I and Van Vlierberghe H: Experimental mouse models for hepatocellular carcinoma research. Int J Exp Pathol 90(4): 367-386, 2009. PMID: 19659896. DOI: 10.1111/j.1365-2613.2009.00656.x 
35 Bakiri L and Wagner EF: Mouse models for liver cancer. Mol Oncol 7(2): 206-223, 2013. PMID: 23428636. DOI: 10.1016/ j.molonc.2013.01.005

36 Lambrecht C, Libbrecht L, Sagaert X, Pauwels P, Hoorne Y, Crowther J, Louis JV, Sents W, Sablina A and Janssens V: Loss of protein phosphatase $2 \mathrm{~A}$ regulatory subunit B56 $\delta$ promotes spontaneous tumorigenesis in vivo. Oncogene 37(4): 544-552, 2018. PMID: 28967903. DOI: 10.1038/onc.2017.350

37 Louis JV, Martens E, Borghgraef P, Lambrecht C, Sents W, Longin S, Zwaenepoel K, Pijnenborg R, Landrieu I, Lippens G, Ledermann B, Götz J, Van Leuven F, Goris J and Janssens V: Mice lacking phosphatase PP2A subunit PR61/B'delta (Ppp2r5d) develop spatially restricted tauopathy by deregulation of CDK 5 and GSK3beta. Proc Natl Acad Sci USA 108(17): 6957-6962, 2011. PMID: 21482799. DOI: $10.1073 /$ pnas.1018777108

38 Janssens V and Goris J: Protein phosphatase 2A: A highly regulated family of serine/threonine phosphatases implicated in cell growth and signalling. Biochem J 353: 417-439, 2001. PMID: 11171037. DOI: 10.1042/0264-6021:3530417

39 Haesen D, Sents W, Lemaire K, Hoorne Y and Janssens V: The basic biology of PP2A in hematologic cells and malignancies. Front Oncol 4: 347, 2014. PMID: 25566494. DOI: 10.3389/fonc.2014. 00347

40 Reynhout S and Janssens V: Physiologic functions of PP2A: lessons from genetically modified mice. Biochim Biophys Acta Mol Cell Res 1866(1): 31-50, 2019. PMID: 30030003. DOI: 10.1016/j.bbamcr.2018.07.010

41 Meeusen B and Janssens V: Tumor suppressive protein phosphatases in human cancer: Emerging targets for therapeutic intervention and tumor stratification. Int J Biochem Cell Biol 96: 98-134, 2018. PMID: 29031806. DOI: 10.1016/j.biocel.2017.10.002

42 Sandgren EP, Quaife CJ, Pinkert CA, Palmiter RD and Brinster RL: Oncogene-induced liver neoplasia in transgenic mice. Oncogene 4(6): 715-724, 1989. PMID: 2543942.

43 Shachaf CM, Kopelman AM, Arvanitis C, Karlsson A, Beer S, Mandl S, Bachmann MH, Borowsky AD, Ruebner B, Cardiff RD, Yang Q, Bishop JM, Contag CH and Felsher DW: MYC inactivation uncovers pluripotent differentiation and tumour dormancy in hepatocellular cancer. Nature 431(7012): 1112-1117, 2004. PMID: 15475948. DOI: 10.1038/nature03043

44 Kaposi-Novak P, Libbrecht L, Woo HG, Lee YH, Sears NC, Coulouarn C, Conner EA, Factor VM, Roskams T and Thorgeirsson SS: Central role of c-MYC during malignant conversion in human hepatocarcinogenesis. Cancer Res 69(7): 2775-2782, 2009. PMID: 19276364. DOI: 10.1158/00085472.CAN-08-3357

45 Lee JS, Chu IS, Mikaelyan A, Calvisi DF, Heo J, Reddy JK and Thorgeirsson SS: Application of comparative functional genomics to identify best-fit mouse models to study human cancer. Nat Genet 36(12): 1306-1311, 2004. PMID: 15565109. DOI: 10.1038/ng1481

46 Martens E, Stevens I, Janssens V, Vermeesch J, Götz J, Goris J and Van Hoof C: Genomic organisation, chromosomal localisation tissue distribution and developmental regulation of the PR61/B' regulatory subunits of protein phosphatase $2 \mathrm{~A}$ in mice. J Mol Biol 336(4): 971-986, 2004. PMID: 15095873. DOI: 10.1016/ j.jmb.2003.12.047

47 Nakashima O, Sugihara S, Eguchi A, Taguchi J, Watanabe J and Kojiro M: Pathomorphologic study of pale bodies in hepatocellular carcinoma. Acta Pathol Jpn 42: 414-418, 1992. PMID: 1323908. DOI: 10.1111/j.1440-1827.1992.tb03246.x
48 Moon WS, Yu HC, Chung MJ, Kang MJ and Lee DG: Pale bodies in hepatocellular carcinoma. J Korean Med Sci 15: 516-520, 2000. PMID: 11068987. DOI: 10.3346/jkms.2000.15.5.516

49 Liu Z, Ma Y, Yang J and Qin H: Upregulated and downregulated proteins in hepatocellular carcinoma: a systematic review of proteomic profiling studies. OMICS 15(1-2): 61-71, 2011. PMID: 20726783. DOI: $10.1089 /$ omi.2010.0061

50 Thorgeirsson SS, Lee JS and Grisham JW: Functional genomics of hepatocellular carcinoma. Hepatology 43: S145-S150, 2006. PMID: 16447291. DOI: 10.1002/hep.21063

51 Hirata H, Sugimachi K, Komatsu H, Ueda M, Masuda T, Uchi R, Sakimura S, Nambara S, Saito T, Shinden Y, Iguchi T, Eguchi H, Ito S, Terashima K, Sakamoto K, Hirakawa M, Honda $\mathrm{H}$ and Mimori K: Decreased expression of fructose-1,6-bisphosphatase associates with glucose metabolism and tumor progression in hepatocellular carcinoma. Cancer Res 76(11): 3265-3276, 2016. PMID: 27197151. DOI: 10.1158/0008-5472.CAN-15-2601

52 Martínez-Chantar ML, Corrales FJ, Martínez-Cruz LA, GarcíaTrevijano ER, Huang ZZ, Chen L, Kanel G, Avila MA, Mato JM and Lu SC: Spontaneous oxidative stress and liver tumors in mice lacking methionine adenosyltransferase 1A. FASEB J 16(10): 1292-1294, 2002. PMID: 12060674. DOI: 10.1096/fj.02-0078fje

53 Martínez-Chantar ML, Vázquez-Chantada M, Ariz U, Martínez N, Varela M, Luka Z, Capdevila A, Rodríguez J, Aransay AM, Matthiesen R, Yang H, Calvisi DF, Esteller M, Fraga M, Lu SC, Wagner $\mathrm{C}$ and Mato JM: Loss of the glycine $N$-methyltransferase gene leads to steatosis and hepatocellular carcinoma in mice. Hepatology 47(4): 1191-1199, 2008. PMID: 18318442. DOI: 10.1002/hep.22159

54 Yamaguchi M, Osuka S, Weitzmann MN, El-Rayes BF, Shoji M and Murata T: Prolonged survival in hepatocarcinoma patients with increased regucalcin gene expression: HepG2 cell proliferation is suppressed by overexpression of regucalcin in vitro. Int J Oncol 49(4): 1686-1694, 2016. PMID: 27633001. DOI: 10.3892/ijo.2016.3669

55 Yamaguchi M and Murata T: Exogenous regucalcin suppresses the growth of human liver cancer HepG2 cells in vitro. Oncol Rep 39(6): 2924-2930, 2018. PMID: 29620227. DOI: 10.3892/ or.2018.6357

56 Hu L, Lau SH, Tzang CH, Wen JM, Wang W, Xie D, Huang M, Wang Y, Wu MC, Huang JF, Zeng WF, Sham JS, Yang M and Guan XY: Association of vimentin overexpression and hepatocellular carcinoma metastasis. Oncogene 23(1): 298-302, 2004. PMID: 14647434. DOI: 10.1038/sj.onc. 1206483

57 Dai Z, Liu YK, Cui JF, Shen HL, Chen J, Sun RX, Zhang Y, Zhou $\mathrm{XW}$, Yang PY and Tang ZY: Identification and analysis of altered alpha1,6-fucosylated glycoproteins associated with hepatocellular carcinoma metastasis. Proteomics 6(21): 5857-5867, 2006. PMID: 17068759. DOI: $10.1002 /$ pmic. 200500707

58 Shirahashi H, Sakaida I, Terai S, Hironaka K, Kusano N and Okita $\mathrm{K}$ : Ubiquitin is a possible new predictive marker for the reoccurence of human hepatocellular carcinoma. Liver 22(5): 413418, 2002. PMID: 12458564. DOI: 10.1034/j.1600-0676.2002. 01541.x

Received August 28, 2020

Revised September 13, 2020

Accepted September 14, 2020 